\title{
Dopaminergic Regulation of Inhibitory and Excitatory Transmission in the Basolateral Amygdala-Prefrontal Cortical Pathway
}

\author{
Stan B. Floresco and Maric T. Tse \\ Department of Psychology and Brain Research Center, University of British Columbia, Vancouver, British Columbia, Canada V6T 1Z4
}

\begin{abstract}
Projections from the basolateral amygdala (BLA) and dopamine (DA) input from the ventral tegmental area (VTA) converge in the medial prefrontal cortex (mPFC), forming a neural circuit implicated in certain cognitive and emotional processes. However, the role that DA plays in modulating activity in the BLA-mPFC pathway is unknown. The present study investigated the mechanisms by which DA modulates BLA-evoked changes in $\mathrm{mPFC}$ neural activity, using extracellular single-unit recordings in urethane-anesthetized rats. BLA stimulation evoked two distinct types of responses in separate populations of mPFC neurons: monosynaptic, excitatory responses and, more commonly, inhibition of spontaneous firing. Stimulation of the VTA or local iontophoretic application of DA attenuated BLAevoked inhibition of PFC neuron firing. Administration of selective DA receptor agonists revealed that these effects were mediated by $D_{2}$ and $\mathrm{D}_{4}$ (but not $\mathrm{D}_{1}$ ) receptors. In addition, VTA stimulation or DA application attenuated BLA-evoked firing of a separate population of mPFC neurons in a frequency-dependent manner; firing evoked by higher-frequency stimulation of the BLA was less inhibited than that evoked by single-pulse stimulation. Attenuation of BLA-evoked firing was also induced by of $\mathrm{D}_{1}$ (but not $\mathrm{D}_{2}$ or $\mathrm{D}_{4}$ ) receptor agonists. These data indicate that dissociable DA receptor mechanisms regulate the balance of excitatory and inhibitory transmission in BLAmPFC circuits, biasing toward an increase in the excitatory influence that the BLA exerts over populations of mPFC neurons. These findings may have important implications for understanding the pathophysiology underlying emotional and cognitive disturbances present in disorders such as depression and drug addiction.
\end{abstract}

Key words: frontal lobes; amygdala; $\mathrm{D}_{2} / \mathrm{D}_{4}$; emotions; depression; drug abuse

\section{Introduction}

Projections from the basolateral nucleus of the amygdala (BLA) to the medial prefrontal cortex ( $\mathrm{mPFC}$ ) form a neural circuit that has been implicated in a number of cognitive and emotional processes, such as the acquisition and extinction of conditioned fear (Maren and Quirk, 2004) and different forms of decisionmaking (Bechara et al., 1999; Floresco and Ghods-Sharifi, 2007). Perturbations in these neural circuits are thought to underlie emotional and cognitive disturbances in diseases such as schizophrenia, depression, and drug addiction (Shenton et al., 2001; Drevets, 2003; Bechara, 2005). The BLA sends glutamatergic projections to multiple subregions of the $\mathrm{MPFC}$, including the anterior cingulate, prelimbic, and infralimbic cortices (McDonald, 1991, 1996; Shinonaga et al., 1994; Conde et al., 1995). These projections synapse on both principle pyramidal neurons and on

\footnotetext{
Received Nov. 1, 2006; revised Jan. 16, 2007; accepted Jan. 22, 2007.

This work was supported by an operating Grant from the Canadian Institutes of Health Research (CIHR) (S.B.F.). S.B.F. is a CIHR New Investigator, a Michael Smith Scholar, and a recipient of a National Alliance for Research on Schizophrenia and Depression Young Investigator Award. We are grateful to Dr. Gemma Dalton for her useful comments on this manuscript.

Correspondence should be addressed to Dr. Stan B. Floresco, Department of Psychology and Brain Research Center, University of British Columbia, 2136 West Mall, Vancouver, British Columbia, Canada V6T 124. E-mail: floresco@psych.ubc.ca.

DOI:10.1523/JNEUROSCI.5474-06.2007

Copyright $\odot 2007$ Society for Neuroscience $\quad$ 0270-6474/07/272045-13\$15.00/0
}

parvalbumin-immunoreactive GABAergic interneurons (Gabbott et al., 2006). Accordingly, in vivo electrophysiological analyses of this pathway have revealed that activation of the BLA can differentially modulate the activity of separate subpopulations of mPFC neurons, inducing either monosynaptic excitatory responses or feedforward inhibition of spontaneous firing (PerezJaranay and Vives, 1991; Ishikawa and Nakamura, 2003; Dilgen and O'Donnell, 2005, 2006).

Mesocortical dopamine (DA) projections from the ventral tegmental area (VTA) overlap with inputs from the BLA (Pinto and Sesack, 1999), indicating that DA may exert modulatory influence over BLA-evoked changes in MPFC neural activity. DA can modulate the activity of MPFC neurons via a number of different receptor subtypes. Expression of $D_{1}$ receptors on pyramidal cells is substantially greater than $D_{2}$-like $\left(D_{2}, D_{4}\right)$ receptors (Gaspar et al., 1995), whereas both types of DA receptors have been localized on GABAergic interneurons (Sesack et al., 1995; Mrzijak et al., 1996; Khan et al., 1998; Muly et al., 1998; Wedzony et al., 2001). In vitro neurophysiological studies indicate that activation of $\mathrm{D}_{1}$ receptors facilitate NMDA-mediated postsynaptic currents but inhibits non-NMDA-mediated responses evoked by local stimulation via presynaptic actions and facilitation of GABAergic activity (Seamans et al., 2001a,b; Wang and O'Donnell, 2001). In contrast, $\mathrm{D}_{2}$ or $\mathrm{D}_{4}$ receptor activity attenuates both GABA-mediated inhibition of mPFC pyramidal neu- 
rons and NMDA-mediated synaptic responses (Seamans et al., 2001b; Wang et al., 2002, 2003). Thus, it is possible that mesocortical DA may modulate changes in mPFC neural activity driven by inputs from the BLA. This contention is supported by behavioral studies showing that lesions of DA terminals or blockade of DA receptors in the $\mathrm{mPFC}$ impairs cognitive functions mediated by BLA-mPFC circuits, such as formation and extinction of fear memories and decision making (Morrow et al., 1999; Pezze et al., 2003; Laviolette et al., 2005; Schweimer et al., 2005; Floresco and Magyar, 2006). Despite this possibility, there have been no studies that have investigated how DA may modulate excitatory and inhibitory activity in the BLA-mPFC pathway in vivo. To address this issue directly, the present study assessed the actions of DA, acting on $\mathrm{D}_{1}, \mathrm{D}_{2}$, and $\mathrm{D}_{4}$ receptors, in modulating BLA-evoked changes in $\mathrm{mPFC}$ neural activity, using in vivo extracellular single-unit recordings.

\section{Materials and Methods \\ Subjects and surgery}

Male Sprague Dawley rats (300-400 g; University of British Columbia animals stores, Vancouver, British Columbia, Canada) were anesthetized with urethane $(1.5 \mathrm{~g} / \mathrm{kg}$, i.p.) and mounted in a stereotaxic frame, with the incisor bar set at $3.3 \mathrm{~mm}$. Body temperature was maintained at $37^{\circ} \mathrm{C}$ with a temperature-controlled heating pad. In all surgical preparations, the scalp was incised and holes were drilled in the skull overlying the mPFC, the BLA, and the VTA. In some preparations, a fourth hole was drilled above the nucleus accumbens (NAc). Concentric bipolar electrical stimulating electrodes (SNE-100; David Kopf Instruments, Tujunga, CA) were implanted into the caudal region of the BLA using the following stereotaxic coordinates (flat skull): BLA electrode, anteroposterior (AP), $-3.1 \mathrm{~mm}$ (bregma); mediolateral (ML), $+5.0 \mathrm{~mm}$; dorsoventral (DV), $-7.2 \mathrm{~mm}$ (cortex) (Paxinos and Watson, 1997). This region was selected for two reasons, the first being that most of the projections from the BLA to the mPFC originate in the more caudal regions of this nucleus (Kita and Kitai, 1990; McDonald, 1991; Conde et al., 1995). Second, projections originating from the $\mathrm{mPFC}$ terminate in the more rostral regions of the BLA (Sesack et al., 1989; McDonald et al., 1996). Thus, by placing our electrodes in the more caudal BLA, we would minimize the possibility that BLA-evoked changes in $\mathrm{MPFC}$ neural firing were attributable to antidromic activation of recurrent axon collaterals originating in the $\mathrm{mPFC}$. In some experiments, we also implanted stimulating electrodes in the VTA (AP, $-5.4 \mathrm{~mm}$; ML, $+0.7 \mathrm{~mm}$; DV, $-7.8 \mathrm{~mm}$ ) and the NAc (AP, $+1.3 \mathrm{~mm}$; ML, $+1.3 \mathrm{~mm}$; DV,$-7.3 \mathrm{~mm}$ ). Animal care and surgical procedures were performed in accordance with the guidelines outlined in the Canadian Council for Animal Care and were approved by the Animal Care Committee of the University of British Columbia.

\section{Extracellular recordings and cell-searching procedures}

Single-barrel extracellular recording microelectrodes were constructed from $2.0 \mathrm{~mm}$ outer diameter borosilicate glass capillary tubing (World Precision Instruments, Sarasota, FL) using a vertical micropipette puller (Narishige, Tokyo, Japan). The tips of the electrodes were broken back against a glass rod to $\sim 1 \mu \mathrm{m}$ tip diameter and filled with $2 \mathrm{M} \mathrm{NaCl}$ containing $2 \%$ Pontamine sky blue dye. The in vivo impedance of the microelectrodes ranged from 5 to $10 \mathrm{M} \Omega$. This impedance range easily detects extracellular action potentials emitted from pyramidal neurons, whereas substantially higher impedance electrodes are required to record from interneurons in the PFC (Tierney et al., 2004).

After a burr hole was drilled overlying the $\mathrm{MPFC}$, the dura was resected and the electrode was lowered into the mPFC with a hydraulic microdrive (coordinates: $+3.8-2.7 \mathrm{~mm}$ anterior from bregma, $0.6-0.8 \mathrm{~mm}$ lateral from the midline, $2.2-5.5 \mathrm{~mm}$ ventral from brain surface). This dorsoventral range passed the electrode through the anterior cingulate, prelimbic, and infralimbic regions of the $\mathrm{mPFC}$. The electrode signal was amplified and filtered $(500-2000 \mathrm{~Hz})$ using an X-Cell3 + microelectrode amplifier (Frederick Haer Company, Bowdoinham, ME). Action potential data were acquired, discriminated from noise, stored, and analyzed using Spike 2 software (Cambridge Electronics Design, Cambridge, UK) running on an Intel-based personal computer with a data acquisition board interface (micro $1401 \mathrm{mk}$ II; Cambridge Electronics Design).

After the glass microelectrodes had been lowered to the dorsal border of the $\mathrm{mPFC}$, a cell-searching procedure began. In this procedure, the microelectrode was lowered incrementally through the $\mathrm{MPFC}$ while stimuli were delivered to the BLA $(800 \mu \mathrm{A})$ at $1.5 \mathrm{~s}$ intervals. Although previous in vitro studies have shown that prolonged low-frequency stimulation can induce long-term depression in the hippocampus (Mulkey and Malenka, 1992), other in vivo studies report that extended bouts of low-frequency stimulation of the hippocampus or BLA does not produce any reliable change in synaptic efficacy in the mPFC (Burette et al., 1997; Maroun and Richter-Levin, 2003). Cathodal constant current pulses (0.2 ms duration) were delivered to the BLA through an Iso-Flex optical isolator via a Master-8 programmable pulse generator (A.M.P.I., Jerusalem, Israel) using the parameters noted below. Once a neuron was encountered, the position of the microelectrode was adjusted to maximize the spike amplitude relative to background noise. We would then stimulate the BLA with at least 50 single pulses and generate peristimulus time histograms (PSTHs). From these histograms, we could determine whether the individual neuron was inhibited, excited, or showed no response to BLA stimulation (see below). For neurons that displayed no change in firing in response to BLA stimulation, we did not record data from that cell and continued the cell-searching procedure.

\section{Characterization of BLA-evoked responses and \\ stimulation protocols}

$B L A \rightarrow m P F C(-)$ neurons. We observed that BLA stimulation could evoke two distinct types of changes in firing in separate populations of mPFC neurons. The more commonly observed response was a robust inhibition of neural activity. We characterized these responses with previously established criteria used by Ishikawa and Nakamura (2003). Specifically, a cell was considered to be inhibited by BLA stimulation if it displayed a complete cessation of spontaneous firing lasting at least 50 $\mathrm{ms}$, with the onset of this inhibition occurring $\sim 30 \mathrm{~ms}$ after BLA stimulation. Hereafter, neurons that displayed this type of response are referred to as BLA $\rightarrow \operatorname{mPFC}(-)$ neurons (Fig. $1 A$ ). This duration of inhibition is similar to the long-lasting evoked IPSPs recorded from PFC neurons in vitro (Seamans et al., 2001b). Only neurons that displayed a spontaneous firing rate of $>0.8 \mathrm{~Hz}$ were used in the data analysis.

Once a neuron that was inhibited by BLA stimulation was isolated, single-pulse stimulation was delivered at $0.67 \mathrm{~Hz}$. In these experiments, data were compiled using a minimum of 50 sweeps, although we typically used 100-200 sweeps, and peristimulus time histograms were generated on-line. Stimulation currents were reduced to a minimum level so that the duration of inhibition was at least $100 \mathrm{~ms}$ (range, 200-950 $\mu \mathrm{A}$; median, $650 \mu \mathrm{A}$ ). Once stable baseline levels of BLA-evoked inhibition were obtained, DA transmission was manipulated by stimulation of the VTA, local iontophoretic application of DA, or systemic administration of DA receptor agonists (see below). We used three parameters derived from the peristimulus time histograms to assess how DA manipulations modulated BLA-evoked inhibition. Our primary measure was the "duration" of inhibition (in milliseconds) as defined by Ishikawa and Nakamura (2003). The duration was calculated from the longest period when spontaneous firing was completely suppressed within the first $200 \mathrm{~ms}$ after BLA stimulation. The second measure was the "onset" of this longest period of inhibition (in milliseconds) after BLA stimulation. A third and complementary measure was the "percentage inhibition of spontaneous firing rate." This last measure was calculated by taking the ratio of the average spontaneous firing rate $200 \mathrm{~ms}$ after BLA stimulation to that observed $200 \mathrm{~ms}$ before BLA stimulation. The firing rates for the prestimulation and poststimulation periods were calculated using the following formula: [(number of spikes observed in the $200 \mathrm{~ms}$ period $\div$ number of sweeps obtained) $\div 200 \mathrm{~ms}$. The percentage change in spontaneous firing rate was calculated using the following formula: [(poststimulation firing rate - prestimulation firing rate $) \div$ prestimulation firing rate $] \times 100$.

Thus, a value of $-100 \%$ indicates a complete cessation of firing in the $200 \mathrm{~ms}$ period after BLA stimulation, whereas a value of $0 \%$ indicates that there was no change in the average firing rate $200 \mathrm{~ms}$ after BLA stimula- 

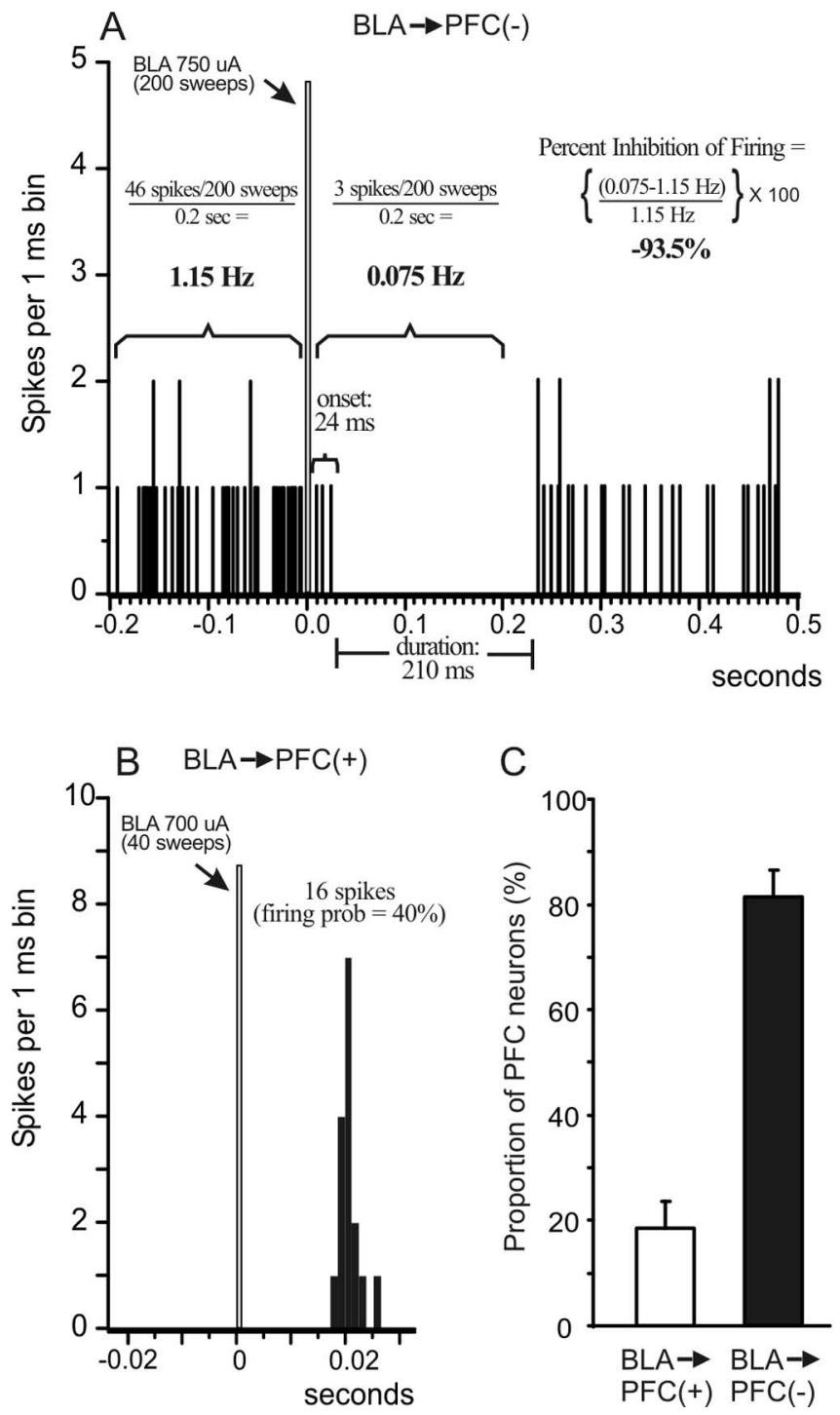

Figure 1. BLA stimulation evokes inhibitory $[\mathrm{BLA} \rightarrow \mathrm{mPFC}(-)]$ and excitatory $[\mathrm{BLA} \rightarrow$ $\mathrm{mPFC}(+)]$ responses in separate populations of $\mathrm{mPFC}$ neurons. $\boldsymbol{A}$, PSTH obtained from a BLA $\rightarrow \mathrm{mPFC}(-)$ neuron over 200 stimulations $(750 \mu \mathrm{A}$ intensity) delivered at $0.67 \mathrm{~Hz}$ (arrow). The figure also diagrams how different parameters of BLA-evoked inhibition were calculated, including the duration and onset of the inhibition, the average prestimulation and poststimulation firing rate, and the percentage inhibition of spontaneous firing. For this and all other PSTHs, the bin width is $1 \mathrm{~ms}$, the gray bar indicates the time point when the BLA was stimulated, and the numbers adjacent to the gray bar represent the stimulation current and number of stimulations (sweeps) delivered to the BLA. B, PSTH obtained from a BLA $\rightarrow \mathrm{mPFC}(+)$ neuron over 40 stimulations ( $700 \mu$ A intensity) delivered at $0.25 \mathrm{~Hz}$ (arrow). The figure also diagrams how BLA-evoked firing probability was calculated. C, Proportions of mPFC neurons that displayed either monosynaptic action potentials (white bar) or an inhibition of spontaneous firing (black bar) in response to BLA stimulation. The majority of $\mathrm{MPFC}$ neurons that responded to BLA stimulation displayed an inhibitory response.

tion compared with the rate $200 \mathrm{~ms}$ before stimulation. The use of these three parameters provides a more complete and reliable index of BLAevoked inhibition than any single measure alone, against which DAmediated changes in this phenomenon can be measured. Changes in these three parameters were used as an index of changes in the inhibitory influence that BLA inputs exert over mPFC neuron firing. An example of a typical inhibitory response recorded from a BLA $\rightarrow \mathrm{mPFC}(-)$ neuron along with how these parameters were calculated are presented in Figure $1 A$.

$B L A \rightarrow m P F C(+)$ neurons. A second group of neurons displayed a fast-onset monosynaptic action potential in response to BLA stimulation [hereafter referred to as $\mathrm{BLA} \rightarrow \operatorname{mPFC}(+)$ neurons] (Fig. $1 B$ ). Of these cells, only those that responded with an orthodromic, monosynaptic response and displayed a signal-to-noise ratio of at least 3:1 were used in the data analysis. Evoked firing was characterized as monosynaptic/ orthodromic if the response (1) displayed spike jitter of at least $2 \mathrm{~ms}$, (2) a shift in spike latency with increasing current amplitude, and (3) followed paired-pulse stimulation at $50 \mathrm{~Hz}$ (otherwise characterized as polysynaptic) but failed to follow $400 \mathrm{~Hz}$ paired-pulse stimulation (otherwise characterized at antidromic) (Pirot et al., 1994; Mulder et al., 1997; Floresco and Grace, 2003). Many of these neurons displayed no or very low rates of spontaneous firing, precluding detection of an inhibitory response after the evoked action potential. For BLA $\rightarrow \mathrm{mPFC}(+)$ neurons that displayed some spontaneous activity, the monosynaptic excitatory response was typically followed by a prolonged period of inhibition, as has been reported previously (Perez-Jaranay and Vives, 1991; Ishikawa and Nakamura, 2003). This is likely attributable to the fact that almost all cortical neurons display a mixed EPSP-IPSP response after afferent pathway stimulation. Despite this effect, these cells were still classified as BLA $\rightarrow \operatorname{mPFC}(+)$ neurons, and we only analyzed the effects of DA manipulations on evoked firing but not the feedforward inhibition.

After establishing that BLA-evoked firing was monosynaptic and orthodromic, stimulation currents were adjusted to submaximal stimulation intensity (range, $200-1000 \mu \mathrm{A}$; median, $700 \mu \mathrm{A}$ ), so that BLA stimulation evoked an action potential $\sim 50-70 \%$ of the time when delivered at $0.25 \mathrm{~Hz}$. In each of these experiments, data were compiled using a minimum of 40 sweeps. Evoked firing probabilities were calculated by dividing the number of evoked spikes by the number of pulses delivered, as has been described previously (Floresco et al., 2001; Floresco and Grace, 2003). Once stable baseline levels of evoked-firing were achieved, DA transmission was manipulated by VTA stimulation, iontophoretic DA application, or systemic administration of DA receptor agonists. Changes in BLA-evoked firing probabilities were used as an index of changes in the excitatory influence that BLA inputs exert over mPFC neuron firing. The spontaneous firing rates for these neurons were calculated in the same manner as was done for BLA $\rightarrow \operatorname{mPFC}(-)$ neurons. An example of a BLA $\rightarrow \mathrm{mPFC}(+)$ neuron and how firing probabilities were calculated are presented in Figure $1 B$.

Antidromic activation. Whenever an mPFC neuron displayed an antidromic spike in response to BLA stimulation, the location and spike latency of that neuron were noted but no other data were taken. For some neurons, we also determined whether these cells projected to either the NAc or the VTA. This was achieved by stimulating the NAc and the VTA with single pulses $(1000-1800 \mu \mathrm{A})$ and then paired-pulse protocols to determine whether these cells were activated antidromically by stimulation of either of these afferent regions of the mPFC.

\section{VTA modulation of BLA-evoked inhibition and excitation of mPFC neurons}

$B L A \rightarrow m P F C(-)$ neurons. For these cells, BLA stimulation intensities were adjusted to evoke a complete cessation of firing with an onset of $\sim 30 \mathrm{~ms}$ and a duration of $150-200 \mathrm{~ms}$. Baseline levels of evoked inhibition were assessed over two to three sweeps of 100-200 pulses delivered at $0.67 \mathrm{~Hz}$. Once stable baseline levels of evoked inhibition were obtained, the VTA was activated in a burst pattern $(20 \mathrm{~Hz}$ train of four pulses, $700 \mu \mathrm{A}) 25 \mathrm{~ms}$ before single-pulse stimulation of the BLA. This combined pattern of stimulation was delivered every 10 s over 50 sweeps. For most of these types of cells, VTA stimulation caused a robust inhibition of spontaneous firing, both before and after BLA stimulation. Thus, we were unable to assess the short-acting $(<200 \mathrm{~ms})$ effects of VTA stimulation on BLA-evoked inhibition. To assess longer-lasting effects (2-10 min) of VTA stimulation on BLA-evoked inhibition of firing, we again stimulated the BLA with single pulses 1 min after repeated VTA stimulation. Current intensities and stimulation frequency were kept constant across baseline and test sweeps (typically two samples, 100-200 sweeps each). In experiments in which more than one neuron was recorded from a rat, we waited at least $30 \mathrm{~min}$ between bouts of VTA stimulation.

$B L A \rightarrow m P F C(+)$ neurons. For these experiments, BLA stimulation 
intensities were adjusted to evoke an action potential $\sim 60-75 \%$ of the time after single-pulse BLA stimulation delivered at $0.25 \mathrm{~Hz}$. Once baseline firing probabilities were obtained, burst stimulation of the VTA was administered $25 \mathrm{~ms}$ before stimulation of the BLA, although in some studies, we systematically varied the delay between the end of the VTA burst and BLA stimulation (25-200 ms). We also assessed whether the effects of VTA stimulation on evoked firing were dependent on the frequency of BLA stimulation. Here, the BLA was stimulated with $20 \mathrm{~Hz}$ trains of five pulses, delivered $20 \mathrm{~ms}$ after VTA burst stimulation, with this combination of VTA-BLA stimulation delivered every $10 \mathrm{~s}$. The 20 $\mathrm{Hz}$ stimulation frequency mimics the way BLA projection neurons fire during reward-related behaviors (Ono et al., 1995; Pratt and Mizumori, 1998). We used a minimum of 25 sweeps to compile the data for all experiments assessing the effects of VTA stimulation on BLA-evoked excitatory responses.

Iontophoretic application of DA. To confirm that the effects of VTA stimulation were mediated by DA acting within the MPFC, separate experiments used iontophoretic application of DA within the region of the recording electrode. Five-barrel microelectrodes were used (World Precision Instruments), with the tips broken back under microscopic control to a final diameter of 3-5 $\mu \mathrm{m}$. The central barrel of the microelectrode was filled with $2 \%$ Pontamine sky blue in $2 \mathrm{M} \mathrm{NaCl}$. One of the outer barrels was filled with $2 \mathrm{M} \mathrm{NaCl}$ for automatic current balancing, and the remaining barrels were filled with $50 \mathrm{~mm}$ DA dissolved in a solution containing $0.2 \mathrm{mg} / \mathrm{ml}$ ascorbic acid. During the cell-searching procedure, DA was retained with negative current of $\sim 5 \mathrm{nA}$ applied with an iontophoretic current generator (model ION 100-T; Dagan, Minneapolis $\mathrm{MN})$. Once either a BLA $\rightarrow \operatorname{mPFC}(-)$ or $\mathrm{BLA} \rightarrow \mathrm{mPFC}(+)$ neuron was isolated, stimulation intensities were adjusted, and stable baseline levels of BLA-evoked inhibition or excitation were established, after which DA was iontophoretically applied continuously with positive current (20 nA). After 1-2 min of DA application, the BLA was again stimulated using the same current intensity that was used during baseline sampling.

Systemic administration of DA receptor agonists. To ascertain the specific DA receptors that mediated the alterations in BLA-evoked activity, separate experiments used intravenous administration of DA agonists selective for $D_{1}, D_{2}$, and $D_{4}$ receptors. Separate groups of rats were implanted with intravenous jugular catheters, consisting of polyethylene 10 tubing attached to a 30 gauge needle and a $1 \mathrm{ml}$ syringe. In these studies, we only obtained data from one neuron per rat, and each rat only received one drug injection. For each type of response, stimulation intensities were adjusted, and stable baseline levels of BLA-evoked inhibition or excitation were established, after which drugs were administered. We would then wait $5 \mathrm{~min}$ after drug injection before stimulating the BLA again using the same current intensity that was used during baseline sampling. For BLA $\rightarrow \mathrm{mPFC}(-)$ neurons, we would typically take $100-$ 200 sweeps before and after drug administration, whereas for BLA $\rightarrow$ $\mathrm{mPFC}(+)$ neurons, we would take $40-150$ sweeps. We tested the effects of four DA receptor agonists: the selective $D_{1}$ receptor agonist SKF 81297 (6-chloro-2,3,4,5-tetrahydro-1-phenyl-1 $\mathrm{H}$-3-benzazepine hydrobromide) $(0.5 \mathrm{mg} / \mathrm{kg}$; Tocris Cookson, Ellisville, $\mathrm{MO})$, the $\mathrm{D}_{2} / \mathrm{D}_{4}$ agonist quinpirole $(0.2 \mathrm{mg} / \mathrm{kg}$; Sigma, Oakville, Ontario, Canada), the selective $\mathrm{D}_{4}$ agonist $\mathrm{PD}$-168,077 ( $N$-[[4-(2-cyanophenyl)-1-piperazinyl]methyl]3-benzazepine-7,8-diol maleate) (1.0 mg/kg; Tocris Cookson), and the selective $\mathrm{D}_{2}$ agonist bromocriptine $(0.5 \mathrm{mg} / \mathrm{kg}$; Sigma). All drugs were dissolved in physiological saline, sonicated until dissolved, and protected from light, with the exception of bromocriptine, which was dissolved in a small volume of DMSO and diluted with saline. The concentrations of these solutions were set so that injection volumes would range between 0.15 and $0.30 \mathrm{ml}$, and no more than one drug injection was given per animal. The doses of these drugs were chosen from previous studies that have shown alterations in either behaviors or neural activity in DA terminal regions when administered systemically at these doses (Maslowski and Napier, 1991; Piercey et al., 1996; Nayak and Cassaday, 2003; Hotte et al., 2006).

\section{Histology}

At the end of each experiment, the recording site in the mPFC was marked via iontophoretic ejection of Pontamine sky blue dye from the tip of the recording electrode (30 $\mu \mathrm{A}$ constant current for 20-30 min). Iron deposits were made in stimulation sites by passing direct current $(100 \mu \mathrm{A}$ for $10 \mathrm{~s}$ ) through the stimulating electrode. After dye ejection, brains were removed and fixed in Formalin containing 0.1\% potassium ferricyanide for at least $24 \mathrm{~h}$. Brains were then sectioned into $50 \mu \mathrm{m}$ coronal slices, mounted, and stained with cresyl violet to enable histological determination of recording and stimulating electrode sites.

\section{Data analysis}

Data from studies using VTA stimulation and iontophoretic application of DA were analyzed using repeated-measures ANOVA, with sample (i.e., baseline vs post-DA manipulation) as a within-subjects factor. Data from studies using systemic administration of DA receptor agonists were analyzed with a two-way between-/within- subjects factorial ANOVA, with drug treatment as the between-subjects factor and sample (baseline and postdrug administration) as the within-subjects factor.

\section{Results}

All of the neurons recorded in this study displayed characteristics typical of juxtacellularly labeled PFC pyramidal neurons recorded extracellularly (Tierney et al., 2004; Tseng et al., 2006). These included action potential widths of $>0.9 \mathrm{~ms}$ and relatively low firing rates (typically $1-3 \mathrm{~Hz}$, depending on neuron type). The spontaneous firing rates of these neurons were in a similar range to those displayed by PFC neurons recorded from awake behaving animals (Homayoun and Moghaddam, 2006).

\section{Population studies of the electrophysiological properties of BLA-mPFC pathway}

One series of experiments investigated the proportion of BLAevoked responses in $\mathrm{mPFC}$ neurons that were either inhibitory or excitatory. In these studies, we made four to six vertical passes of the recording electrode through the $\mathrm{mPFC}$ while stimulating the BLA at $0.67 \mathrm{~Hz}$, using a set stimulation current of $800 \mu \mathrm{A}$. Whenever a neuron that was responsive to BLA stimulation was encountered, the BLA was stimulated with 100 pulses to determine whether the neuron responded with inhibition or excitation. When passing the electrode through the entire dorsal/ventral extent of the medial mPFC, we observed on average $4.0 \pm 0.6$ neurons per electrode track that were responsive in some manner to BLA stimulation ( $n=167$ neurons recorded from 16 rats). In these rats, $>80 \%$ of these neurons displayed an inhibition of spontaneous activity after BLA stimulation, with the remaining proportion of cells showing a monosynaptic excitatory response. Thus, as has been reported previously (Perez-Jaranay and Vives, 1991; Ishikawa and Nakamura, 2003), activation of BLA inputs exerts a net inhibitory effect on neural firing of populations of mPFC pyramidal neurons, presumably via disynaptic pathways incorporating GABAergic interneurons (Gabbott et al., 2006). In contrast, only a minority of $\mathrm{mPFC}$ neurons receive sufficient excitatory input from the BLA capable of evoking spike firing, although it is likely that a greater proportion of these neurons do receive direct glutamatergic inputs from the BLA that may evoke subthreshold EPSPs (Dilgen and O’Donnell, 2005, 2006).

\section{Dopaminergic modulation of BLA $\rightarrow \operatorname{mPFC}(-)$ neurons}

We tested the effects of various dopaminergic manipulations on $48 \mathrm{BLA} \rightarrow \mathrm{mPFC}(-)$ neurons. The average baseline firing rate of these cells was $3.3 \pm 0.4 \mathrm{~Hz}$, and the average duration and onset of BLA-evoked inhibition was $182.7 \pm 11$ and $29.7 \pm 3 \mathrm{~ms}$, respectively. 

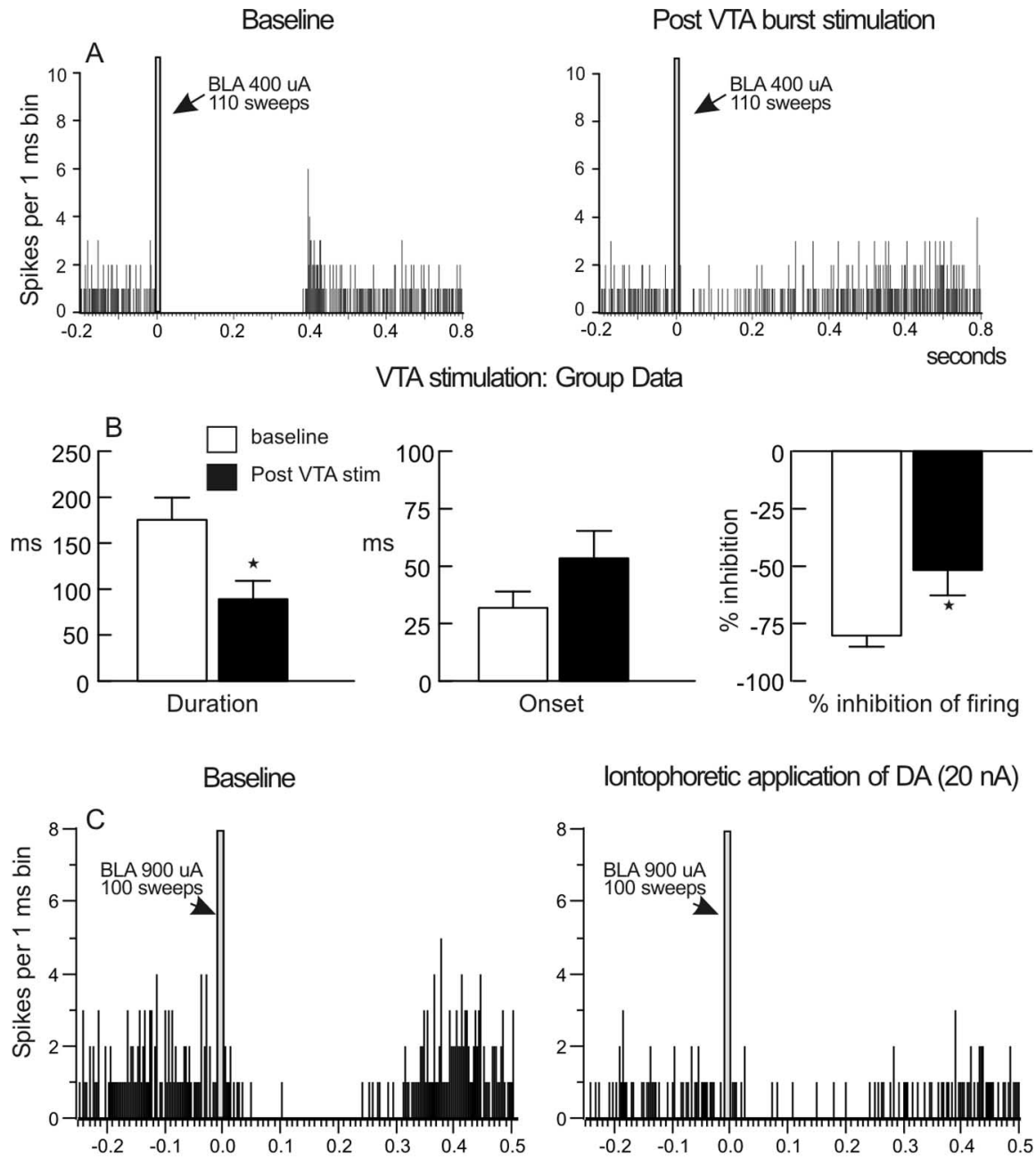

lontophoretic application of DA (20 nA)

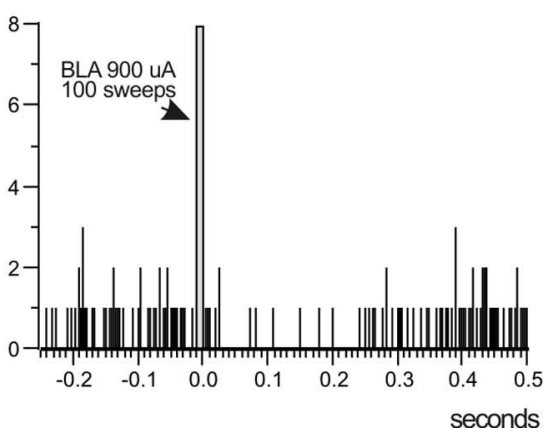

Figure 2. Endogenous or exogenous DA attenuates BLA-evoked inhibition of mPFC neurons. A, PSTH obtained from one neuron before (baseline; left) or 2 min after repeated burst stimulation of the VTA (right). Repeated burst stimulation of the VTA caused a persistent attenuation of BLA-evoked inhibition. $B$. Histograms displaying the mean \pm SEM duration (left), onset (middle), and BLA-evoked percentage change in the spontaneous firing rate (\% inhibition of firing; right) during baseline sweeps (white bars) and after repeated burst stimulation of the VTA (black bars). ${ }^{*} p<0.05$ versus baseline. $n=11$ neurons recorded from 10 rats. $C$, PSTH obtained from one neuron before (baseline; left) and after iontophoretic application of DA $(20 \mathrm{nA})$ near the region of the recording electrode (right). Local application of DA also attenuated BLA-evoked inhibition of $\mathrm{mPFC}$ neural firing.

\section{VTA stimulation}

In these studies, stable baseline levels of evoked inhibition were obtained, after which we stimulated the VTA with 50 bursts to evoke a robust increase in mPFC DA extracellular levels (Garris and Wightman, 1994; Lavin et al., 2005). Two minutes after VTA stimulation, we again stimulated the BLA to assess changes in evoked inhibition of mPFC neural firing. In all neurons tested ( $n=11$ from 10 rats), repeated burst stimulation of the VTA caused a pronounced decrease in BLA-evoked inhibition (Fig. $2 A, B$ ). Specifically, activation of DA neurons significantly reduced the duration of the inhibition $\left(F_{(1,10)}=7.95 ; p=0.018\right)$ (Fig. $2 B$, left), although this manipulation did not cause a statistically significant change in the onset of inhibition $\left(F_{(1,10)}=4.31 ; p=0.065\right)$ (Fig. $2 B$, middle) but significantly reduced the percentage inhibition of spontaneous firing rate $\left(F_{(1,10)}=5.64 ; p=0.039\right)$ (Fig. $2 B$, right). This effect was apparent 2 min after VTA stimulation and returned to baseline after $\sim 10 \mathrm{~min}$. The attenuation of BLA-evoked inhibition was not accompanied by a reliable change in the baseline firing rate of $\mathrm{BLA} \rightarrow \mathrm{mPFC}(-)$ neurons (baseline, $2.6 \pm 0.5 \mathrm{~Hz}$; after VTA stimulation, $4.1 \pm 1 \mathrm{~Hz} ; F_{(1,10)}$ $=1.82 ; p=0.207)$. However, of the 11 neurons tested in this manner, VTA stimulation led to a notable increase in spontaneous firing $(+273 \pm 2 \%)$ in four neurons but caused no change or a slight decrease in the firing rate of the remaining seven neurons $(-14 \pm 15 \%)$. Despite these opposing changes in firing rates, separate two-way ANOVAs confirmed that the magnitude of the effect of VTA stimulation on these parameters did not differ between neurons that showed an increase in firing rate and those that did not (duration, $F_{(1,9)}=0.52, p=0.489$; percentage inhibition, $\left.F_{(1,9)}=0.03, p=0.866\right)$. This indicates that the attenuation of BLAevoked inhibition induced by VTA stimulation was not attributable to changes in the spontaneous firing rates of these cells. Thus, the release of endogenous DA by VTA burst stimulation attenuates BLAevoked inhibition of spontaneous firing that occurs in a subpopulation of $\mathrm{mPFC}$ neurons. This phenomenon persists for a number of minutes after stimulation of the VTA has ceased, consistent with the notion that DA acts on metabotropic, Gprotein-coupled receptors to attenuate inhibitory transmission in the mPFC (Seamans et al., 2001b; Trantham-Davidson et al., 2004).

\section{Iontophoretic application of DA}

To confirm that the effects of VTA stimulation were mediated by DA, we iontophoretically applied DA locally within the region of the recording electrode. In all neurons tested ( $n=6$ from 4 rats), local application of DA substantially reduced the duration of BLA-evoked inhibition $\left(F_{(1,5)}=32.89 ; p=0.002\right)$ (Fig. $2 C$, Table 1). However, application of DA did not significantly alter the onset of inhibition $\left(F_{(1,5)}=0.43 ; p=0.541\right)$ (Table 1$)$ and reduced the percentage inhibition of spontaneous firing rate in five of six $(83 \%)$ of neurons tested, although this effect did not achieve statistical significance $\left(F_{(1,5)}=2.18 ; p=0.20\right)$ (Table 1$)$. Furthermore, we did not observe a statistically significant change in the spontaneous firing rate in these neurons $\left(F_{(1,5)}=2.31 ; p=\right.$ 0.189 ) (Table 1). Thus, local iontophoresis of DA attenuates the duration of BLA-evoked inhibition, although this manipulation was less effective than VTA stimulation in attenuating our two other measures of BLA-evoked inhibition. This may be attributable to the fact that iontophoresis induces a spatially restricted increase in DA around the region of the recording electrode, whereas VTA stimulation would be expected to enhance DA release throughout the mPFC. Thus, iontophoresis of DA would be less likely to activate DA receptors farther away from the electrode tip, such as those on distal dendrites of pyramidal neurons, presynaptic GABA or glutamate terminals, or GABAergic interneurons. However, the observation that the duration of BLAevoked inhibition was substantially and reliably reduced by local 
Table 1. Mean \pm SEM changes in BLA-evoked firing for BLA $\rightarrow \mathrm{mPFC}(-)$ and BLA $\rightarrow \mathrm{mPFC}(+)$ neurons before and after local iontophoretic application of $\mathrm{DA}$

\begin{tabular}{lcc}
\hline BLA $\rightarrow$ mPFC $(-)$ neurons $(n=6)$ & Baseline & After DA application \\
\hline Duration of inhibition (ms) & $212.0 \pm 35$ & $82.7 \pm 21^{*}$ \\
Onset of inhibition (ms) & $31.2 \pm 10$ & $41.8 \pm 22$ \\
\% inhibition of spontaneous firing & $79.6 \pm 9 \%$ & $61.4 \pm 18 \%$ \\
Spontaneous firing rate $(\mathrm{Hz})$ & $3.6 \pm 1.0$ & $2.4 \pm 0.4$ \\
\hline BLA $\rightarrow$ mPFC $(+)$ neurons $(n=3)$ & Baseline & After DA application \\
\hline Evoked firing probability $(\%)$ & $42 \pm 3 \%$ & $27 \pm 2 \%{ }^{*}$ \\
Spontaneous firing rate $(\mathrm{Hz})$ & $4.0 \pm 0.9$ & $2.5 \pm 1.0$ \\
\hline${ }^{*} p<0.05$ versus baseline. & &
\end{tabular}

Table 2. Mean \pm SEM spontaneous firing rates $(\mathrm{Hz})$ of $\mathrm{BLA} \rightarrow \mathrm{mPFC}(-)$ and BLA $\rightarrow \mathrm{mPFC}(+)$ neurons before and after systemic $\mathrm{DA}$ receptor agonist administration

\begin{tabular}{lll}
\hline BLA $\rightarrow$ mPFC( $(-)$ neurons & Baseline & After drug administration \\
\hline Saline $(n=7)$ & $3.8 \pm 0.7$ & $2.7 \pm 0.8$ \\
SKF $81297(0.5 \mathrm{mg} / \mathrm{kg})(n=5)$ & $2.8 \pm 0.8$ & $2.3 \pm 0.4$ \\
Quinpirole $(0.2 \mathrm{mg} / \mathrm{kg})(n=6)$ & $3.1 \pm 1.3$ & $2.4 \pm 0.9$ \\
Bromocriptine $(0.5 \mathrm{mg} / \mathrm{kg})(n=6)$ & $4.6 \pm 2.0$ & $3.0 \pm 1.0$ \\
PD-168,077 $(1 \mathrm{mg} / \mathrm{kg})(n=7)$ & $2.9 \pm 0.6$ & $3.8 \pm 1.1$ \\
\hline BLA $\rightarrow$ mPFC $(+)$ neurons & Baseline & After drug administration \\
\hline SKF $81297(0.5 \mathrm{mg} / \mathrm{kg})(n=9)$ & $1.0 \pm 0.3$ & $1.0 \pm 0.6$ \\
Quinpirole $(0.2 \mathrm{mg} / \mathrm{kg})(n=7)$ & $0.7 \pm 0.2$ & $1.5 \pm 0.5^{*}$ \\
PD-168,077 $(1 \mathrm{mg} / \mathrm{kg})(n=7)$ & $1.4 \pm 0.6$ & $2.7 \pm 1.3$ \\
\hline
\end{tabular}

${ }^{*} p<0.05$ versus baseline.

application of DA suggests that this measure may be modulated by DA acting on receptors located on postsynaptic pyramidal neurons.

Systemic administration of DA agonists and saline controls To clarify the specific DA receptor subtypes that modulate BLAevoked inhibition, we used systemic administration of selective DA receptor agonists. We tested the effects of four agonists and also included a saline control group to confirm that any changes in BLA-evoked inhibition were not attributable to repeated stimulation of the BLA. Analysis of these data revealed significant drug treatment by sample interactions for all three measures of BLA-evoked inhibition (i.e., duration, $F_{(4,24)}=3.83, p=0.015$; onset, $F_{(4,24)}=3.57, p=0.020$; percentage inhibition of firing rate, $\left.F_{(4,24)}=4.65, p=0.006\right)$. Saline injections $(n=7)$ did not alter any measures of BLA-evoked inhibition. Neither the duration (baseline, $219 \pm 32 \mathrm{~ms}$ vs postinjection, $235 \pm 21 \mathrm{~ms}$ ), the onset (baseline, $38 \pm 16 \mathrm{~ms}$ vs postinjection, $25 \pm 16 \mathrm{~ms}$ ), nor the percentage inhibition of firing rate (baseline, $-86 \pm 4 \%$ vs postinjection, $-86 \pm 3 \%$ ) were altered after a saline injection (all $p$ values $\geq 0.334$ ). Furthermore, under control conditions, repeated stimulation of the BLA did not cause any significant change in the baseline firing rate of these neurons $\left(t_{(6)}=0.86 ; p=\right.$ 0.42 ) (Table 2). Thus, repeated single-pulse stimulation of the BLA does not lead to changes in either BLA-evoked inhibition or the spontaneous firing rates of $\mathrm{BLA} \rightarrow \mathrm{mPFC}(-)$ neurons over time.

Administration of the $\mathrm{D}_{1}$ receptor agonist SKF 81297 (0.5 $\mathrm{mg} / \mathrm{kg} ; n=5$ ) did not alter significantly any of the three measures of BLA-evoked inhibition (all $p$ values $\geq 0.13$ ) (Fig. $3 A, B$ ), indicating that this DA receptor subtype does not play a prominent role in modulation BLA-evoked inhibition of mPFC neurons. In contrast, the $\mathrm{D}_{2} / \mathrm{D}_{4}$ agonist quinpirole $(0.2 \mathrm{mg} / \mathrm{kg})$ significantly attenuated all measures of BLA-evoked inhibition in all neurons tested $(n=6)$. Specifically, quinpirole reduced the duration of inhibition $(p=0.007)$ (Fig. $3 C$, left), increased the onset $(p=$ 0.002 ) (Fig. $3 C$, middle), and attenuated the percentage inhibition of spontaneous firing rate $(p=0.012)$ (Fig. $3 C$, right, $D)$.

To determine whether the effects of quinpirole were mediated by either $\mathrm{D}_{2}$ or $\mathrm{D}_{4}$ receptors or both (Tang et al., 1994), we tested the effects of the selective $\mathrm{D}_{4}$ agonist $\mathrm{PD}-168,077$ and the $\mathrm{D}_{2}$ agonist bromocriptine. The relative affinity of PD-168,077 for $\mathrm{D}_{4}$ receptors is $>400$-fold greater compared with $\mathrm{D}_{2}$ receptors (Glase et al., 1997), whereas the affinity of bromocriptine for $\mathrm{D}_{2}$ receptors is two orders of magnitude greater than for $\mathrm{D}_{4}$ receptors (Seeman and Van Tol, 1993). In a separate group of rats, administration of bromocriptine $(0.5 \mathrm{mg} / \mathrm{kg} ; n=6)$ reduced both the duration of inhibition ( $p=0.0003$ ) (Fig. 3E, left) and the percentage inhibition of spontaneous firing rate $(p=0.003)$ (Fig. $3 E$, right, $3 F$ ) but did not alter the onset of the inhibition $(p=0.781)$ (Fig. 3E, middle). Conversely, the actions of PD-168,077 ( $1 \mathrm{mg} / \mathrm{kg} ; n=7)$ were similar to that of quinpirole in that this compound attenuated all three measures of BLA-evoked inhibition (duration, $p=0.0003$; onset, $p=0.009$; percentage inhibition of firing, $p<0.0001$ ) (Fig. $3 G, H$ ). A separate analysis was conducted on the effects of these drugs on baseline firing rates. There was no significant main effect of drug treatment, sample, or drug by sample interactions (all $F$ values $\leq 2.1$; all $p$ values $\geq 0.108$ ) (Table 2 ). This indicates that that none of these DA agonists altered the spontaneous firing rates of $\mathrm{mPFC}$ neurons in a manner that differed from saline control treatments. Thus, activation of $\mathrm{D}_{2}$ or $\mathrm{D}_{4}$ (but not $\mathrm{D}_{1}$ ) receptors attenuates BLA-evoked inhibition of firing that occurs in a subpopulation of $\mathrm{mPFC}$ neurons. This action of $\mathrm{D}_{2} / \mathrm{D}_{4}$ receptors may in turn increase the influence that monosynaptic excitatory inputs from the BLA exert over mPFC neural firing. Support for this notion comes from the finding that administration of quinpirole revealed a monosynaptic excitatory response in one neuron that initially displayed only an inhibition of firing in response to BLA stimulation (Fig. 3I).

\section{Dopaminergic modulation of $\mathrm{BLA} \rightarrow \mathrm{mPFC}(+)$ neurons}

We tested the effects of various dopaminergic manipulations on $\mathrm{BLA}$-evoked firing in $44 \mathrm{BLA} \rightarrow \mathrm{mPFC}(+)$ neurons. The average baseline firing rate of these cells was substantially lower than that observed for BLA $\rightarrow \mathrm{mPFC}(-)$ neurons $(1.9 \pm 0.4 \mathrm{~Hz})$. Approximately $50 \%$ of these neurons displayed very low rates of spontaneous firing $(0-0.8 \mathrm{~Hz})$, and, thus, no inhibitory response could be detected. The remaining neurons typically did display an inhibition of spontaneous firing after the initial excitatory response, similar to evoked EPSP-IPSP sequence observed in cortical neurons. However, for these cells, we only characterized the effects of dopaminergic manipulations on evoked firing. The average latency of the evoked excitatory response was $13 \pm 0.5 \mathrm{~ms}$.

\section{VTA stimulation}

Burst stimulation of the VTA, 25 ms before single-pulse stimulation of the BLA, produced a robust suppression $(-95 \pm 4 \%)$ of BLA-evoked firing in all BLA $\rightarrow \operatorname{mPFC}(+)$ neurons tested $(n=9$ from 7 rats; $F_{(1,8)}=76.49 ; p=0.0001$ ) (Fig. $4 A$ ). However, as opposed to what was observed for BLA $\rightarrow \operatorname{mPFC}(-)$ neurons, the inhibition of BLA-evoked firing did not persist after VTA stimulation had ceased. When tested 2 min after repeated VTA stimulation, the evoked firing probability of these neurons did not differ significantly from baseline in eight neurons tested $\left(F_{(1,7)}=0.41 ; p=0.542\right)$ (Fig $4 A$, gray bar). Thus, as has been reported for hippocampal-evoked firing in the MPFC (Jay et al., 


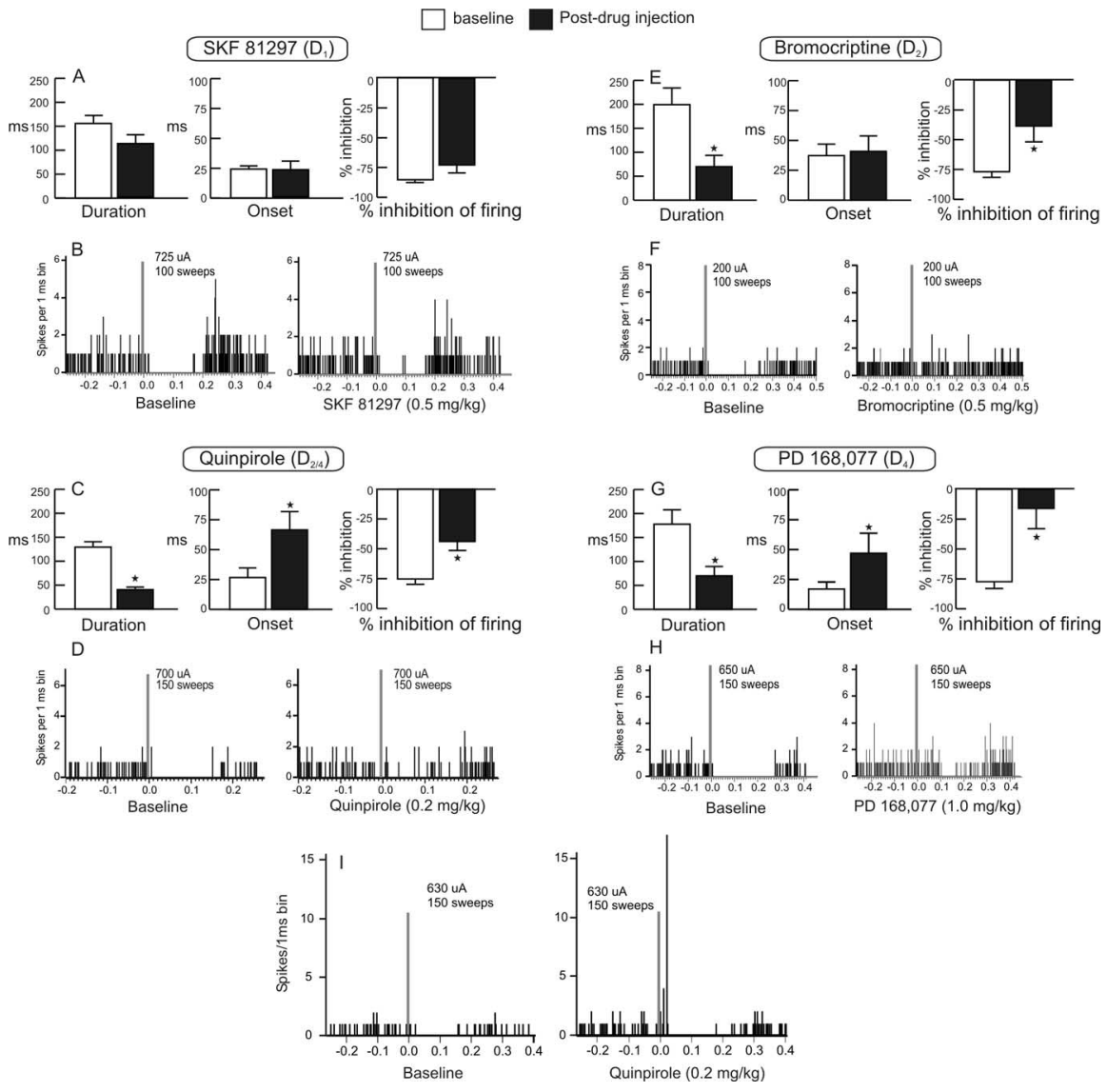

Figure 3. Administration of $D_{2}$ or $D_{4}$ (but not $D_{1}$ ) DA receptor agonists attenuates BLA-evoked inhibition of mPFC neurons. $A$, $\boldsymbol{C}, \boldsymbol{E}, \mathbf{G}$, Mean \pm SEM duration (left), onset (middle), and percentage inhibition of firing during baseline sweeps (white bars) and after systemic administration DA agonists selective for $D_{1}(\boldsymbol{A})\left(\right.$ SKF 81297), $D_{2} / D_{4}(C)$ (quinpirole), $D_{2}(\boldsymbol{E})$ (bromocriptine), and $D_{4}$ (G) $\left(\right.$ PD-168,077) receptors (black bars). ${ }^{*} p<0.05$ versus baseline. $\boldsymbol{B}, \boldsymbol{D}, \boldsymbol{F}, \boldsymbol{H}$, PSTHs obtained from individual neurons before (baseline; left) or 5 min after administration of SKF 81297, quinpirole, bromocriptine, or PD-168,077, respectively (right). I, PSTH obtained from one neuron during baseline stimulation (left) and after intravenous injection of quinpirole (right). Note that this neuron only displayed inhibition of firing in response to BLA stimulation initially but that administration of quinpirole revealed a robust monosynaptic excitatory response.

1995; Gurden et al., 1999; Floresco and Grace, 2003), burst stimulation of the VTA induces a dramatic suppression of firing evoked by single-pulse stimulation of BLA. However, in contrast to what was observed in $\mathrm{BLA} \rightarrow \mathrm{mPFC}(-)$ neurons, this suppression of evoked firing was relatively short lasting and did not persist after stimulation of the VTA had ceased.

Intracellular recordings from $\mathrm{mPFC}$ neurons in vivo have shown that VTA stimulation can induce either a brief $(<50 \mathrm{~ms})$ EPSP-IPSP sequence (mediated by glutamate and GABA) or a prolonged (seconds) $D_{1}$ receptor-mediated depolarization after burst stimulation (Lewis and O'Donnell, 2000; Lavin et al., 2005). We sought to determine whether adjusting the interval between VTA and BLA stimulation would alter the magnitude of the suppression of BLA-evoked firing. In a separate group of neurons ( $n=9$ from 5 rats), we systematically adjusted the interval between the end of the VTA burst and single-pulse simulation of the BLA in a counterbalanced manner. Analysis of these data with a two-way repeated-measures ANOVA revealed a significant sample by interval interaction $\left(F_{(4,32)}=5.38 ; p=0.002\right)$. As can be seen from Figure $4 B$, extending the interval between VTA and BLA stimulation reduced the suppression of BLA-evoked firing. However, at the longest interval tested (200 ms), VTA stimulation still caused a significant decrease in the BLA-evoked firing probability $(-38 \pm 13 \% ; p=0.041)$. Based on previous studies
(Lewis and O'Donnell, 2000; Lavin et al., 2005), it would be expected that a fast IPSP induced by VTA stimulation would have returned to baseline after this long an interval. Thus, although we cannot rule out that the inhibition of BLA-evoked firing induced by VTA stimulation is mediated partially by GABAergic mechanisms, these findings suggest that part of this effect may also be attributable to the release of mesocortical DA.

\section{Iontophoretic application of DA}

In a separate group of cells, DA was applied iontophoretically within the region of the recording electrode. In these experiments, it was particularly difficult to encounter $\mathrm{BLA} \rightarrow \mathrm{PFC}(+)$ neurons, likely attributable to the fact that larger multibarrel recording electrodes cause more cellular damage when lowered through cortex, and only a minority of cells responding to BLA stimulation display excitation $(\sim 20 \%)$. Despite the low yield of these experiments, we were able to record from three $\mathrm{BLA} \rightarrow \mathrm{PFC}(+)$ neurons in three separate rats. In all neurons tested (100\%), local application of DA caused a statistically significant reduction in the BLA-evoked firing probability, by an average of $-36 \pm 4 \%\left(F_{(1,2)}=67.01\right.$; $p=0.014$ ) (Fig. 4C, Table 1 ). This effect was not accompanied by a statistically significant change in the spontaneous firing rate of these cells $\left(F_{(1,2)}=11.89 ; p=\right.$ 0.075) (Table 1). Thus, as was observed after VTA stimulation, local application of DA attenuates BLA-evoked firing in a subpopulation of mPFC neurons. When comparing these effects with those reported above, the suppression of firing induced by VTA stimulation 25 ms before BLA stimulation was substantially greater than that induced by local DA application. However, when the interval between VTA and BLA stimulation was increased, the suppression of BLA-evoked firing was similar to that observed after iontophoretic application of DA. This further supports the notion that the release of DA by VTA burst stimulation contributes to the suppression of $\mathrm{mPFC}$ neural firing driven by inputs from the BLA.

The above results indicate that DA suppresses mPFC neural firing evoked by single-pulse stimulation of the BLA. However, a number of in vivo and in vitro electrophysiological studies have shown that modulation by DA of evoked excitatory responses in the $\mathrm{mPFC}$ is dependent on the frequency at which excitatory inputs are activated (Jay et al., 1995; Gurden et al., 1999; Seamans et al., 2001a; Floresco and Grace, 2003; Seamans and Yang, 2004). In light of these data, we assessed the effects of burst stimulation of the VTA on evoked firing when the BLA was stimulated with a higher-frequency train of pulses (five pulses at $20 \mathrm{~Hz}$ ) in an attempt to mimic the way BLA neurons fire in response to rewarding stimuli (Ono et al., 1995; Pratt and Mizumori, 1998). Analysis of these data with a two-factor ANOVA yielded a significant sample (baseline vs VTA stimulation) by pulse interaction $\left(F_{(4,20)}=\right.$ 

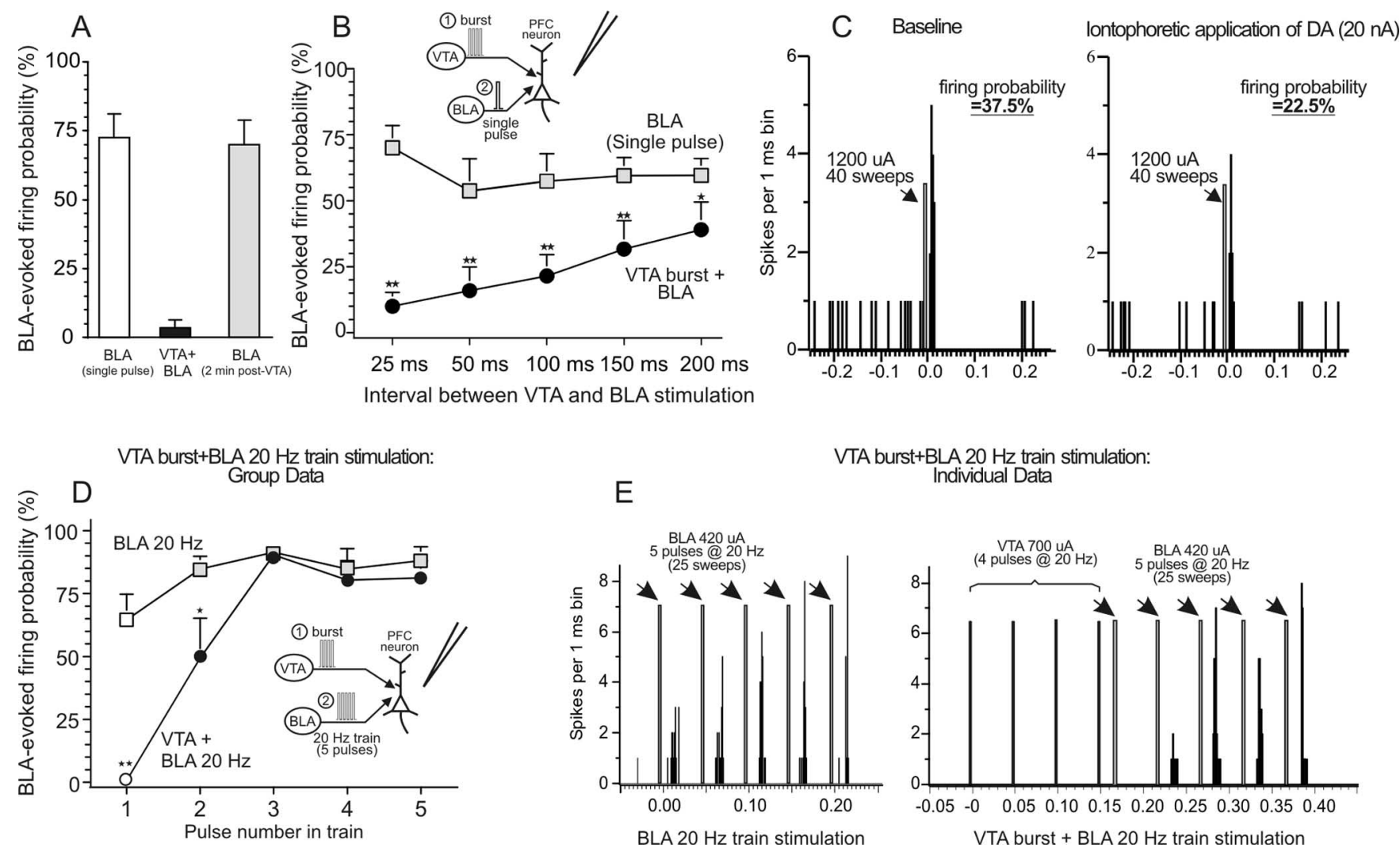
TA burst+BLA $20 \mathrm{~Hz}$ train stimulation:
Individual Data

Figure 4. Endogenous or exogenous DA attenuates BLA-evoked firing of $\mathrm{MPFC}$ neurons. $A$, Mean \pm SEM firing probability evoked by single-pulse stimulation of the BLA alone (white bar) or after burst stimulation of the VTA administered $25 \mathrm{~ms}$ before BLA stimulation (black bar). VTA stimulation robustly inhibited BLA evoked firing, but this effect did not persist 2 min after VTA stimulation (gray bar). $n=9$ neurons recorded from 7 rats. $\boldsymbol{B}$, Mean \pm SEM firing probability evoked by single-pulse stimulation of the BLA alone (gray squares) or after burst stimulation of the VTA administered 25,50,100, 150, or $200 \mathrm{~ms}$ before BLA stimulation (black circles). Increasing the interval between VTA and BLA stimulation reduced the suppression of evoked firing, but this effect was still prominent $200 \mathrm{~ms}$ after VTA stimulation. ${ }^{*} p<0.05,{ }^{* *} p<0.01$. Inset diagrams stimulation protocol used in this experiment. The VTA was stimulated in a burst pattern (1) at varying intervals before single-pulse stimulation of the BLA (2). $n=9$ neurons recorded from 5 rats. C, PSTH obtained from one neuron during baseline stimulation (left) or after iontophoretic application of DA (20 $\mathrm{nA}$ ) near the region of the recording electrode (right). In this neuron, local application of DA reduced the BLA-evoked firing probability by $40 \%$. D, Mean \pm SEM firing probability evoked by each pulse of a five pulse, $20 \mathrm{~Hz}$ train delivered to the BLA. Squares represent firing probability for each pulse delivered to the BLA alone, and circles represent firing probability when the VTA was stimulated before the BLA. Filled symbols denote significant $(p<0.05)$ difference in firing probability evoked by latter pulses in the train compared with the first pulse (white symbols). ${ }^{*} p<0.05,{ }^{* *} p<0.01$, significant difference versus firing probabilities evoked by the same pulse in the train with and without VTA stimulation. Inset diagrams of the stimulation protocol used in this experiment. Here, the VTA was stimulated in a burst pattern (1) before $20 \mathrm{~Hz}$ train stimulation of the BLA (2). $n=6$ neurons recorded from 6 rats. E, PSTH obtained from one neuron during $20 \mathrm{~Hz}$ train stimulation of the BLA alone (left) or $20 \mathrm{~ms}$ after burst stimulation of the VTA (right). Note how VTA stimulation completely suppressed firing evoked by the first pulse but that this suppression was reduced for the second pulse and no longer apparent after the third pulse.

$15.49 ; p<0.0001$ ). In six neurons tested in this manner ( six rats), $20 \mathrm{~Hz}$ stimulation of the BLA alone caused a progressive and significant $(p=0.006)$ increase in the evoked firing probability over each pulse in the $20 \mathrm{~Hz}$ train. Burst stimulation of the VTA $20 \mathrm{~ms}$ before BLA train stimulation altered this firing profile. VTA activation caused a near-complete suppression of firing evoked by the first of the five pulses delivered to the BLA when compared with the firing probability evoked by the first pulse when no VTA stimulation was delivered (Fig. 4D,E). However, the probability of firing evoked by the second pulse in the train was significantly less attenuated compared with the first pulse, and firing evoked by the latter pulses in the train was no longer inhibited by VTA stimulation. It is notable that, with this stimulation protocol, the interval between the end of the VTA burst and the latter pulses of the BLA train was 120-220 ms; at these time points, BLA-evoked firing was not inhibited. However, as mentioned above, evoked firing was significantly suppressed when VTA stimulation was administered 100-200 ms before single-pulse stimulation of the BLA. These data indicate that suppression of BLA-evoked firing in $\mathrm{MPFC}$ neurons induced by activation of the VTA is frequency dependent. Thus, burst stimu- lation of the VTA robustly suppresses firing evoked by singlepulse BLA stimulation. However, if impulse traffic in the BLAmPFC pathway occurs as a higher-frequency train of action potentials, the VTA-mediated inhibition is no longer apparent in the latter portions of the train.

\section{Systemic administration of DA agonists}

In a separate series of experiments, we investigated the effects of systemic administration of selective DA receptor agonists on BLA-evoked firing. Activation of $D_{1}$ receptors with SKF 81297 $(0.5 \mathrm{mg} / \mathrm{kg})$ attenuated BLA-evoked firing in six of nine $(67 \%)$ neurons tested (Fig. 5A,B). The magnitude of this effect was similar to that induced by iontophoretic application of DA (i.e., a $-36.1 \pm 12 \%$ decrease of baseline firing probability), and analysis of the group data confirmed this effect was statistically reliable $\left(F_{(1,8)}=7.59 ; p=0.024\right)$. However, this effect was not accompanied by a change in the spontaneous firing rate of these neurons $\left(F_{(1,8)}=0.04 ; p=0.847\right)$ (Table 2$)$. In contrast, activation of $\mathrm{D}_{2} / \mathrm{D}_{4}$ receptors with quinpirole $(0.2 \mathrm{mg} / \mathrm{kg} ; n=7)$ did not alter BLA-evoked firing $\left(F_{(1,6)}=0.19 ; p=0.678\right)$ (Fig. $5 A$ ) but did cause a significant increase in the baseline firing rate of 

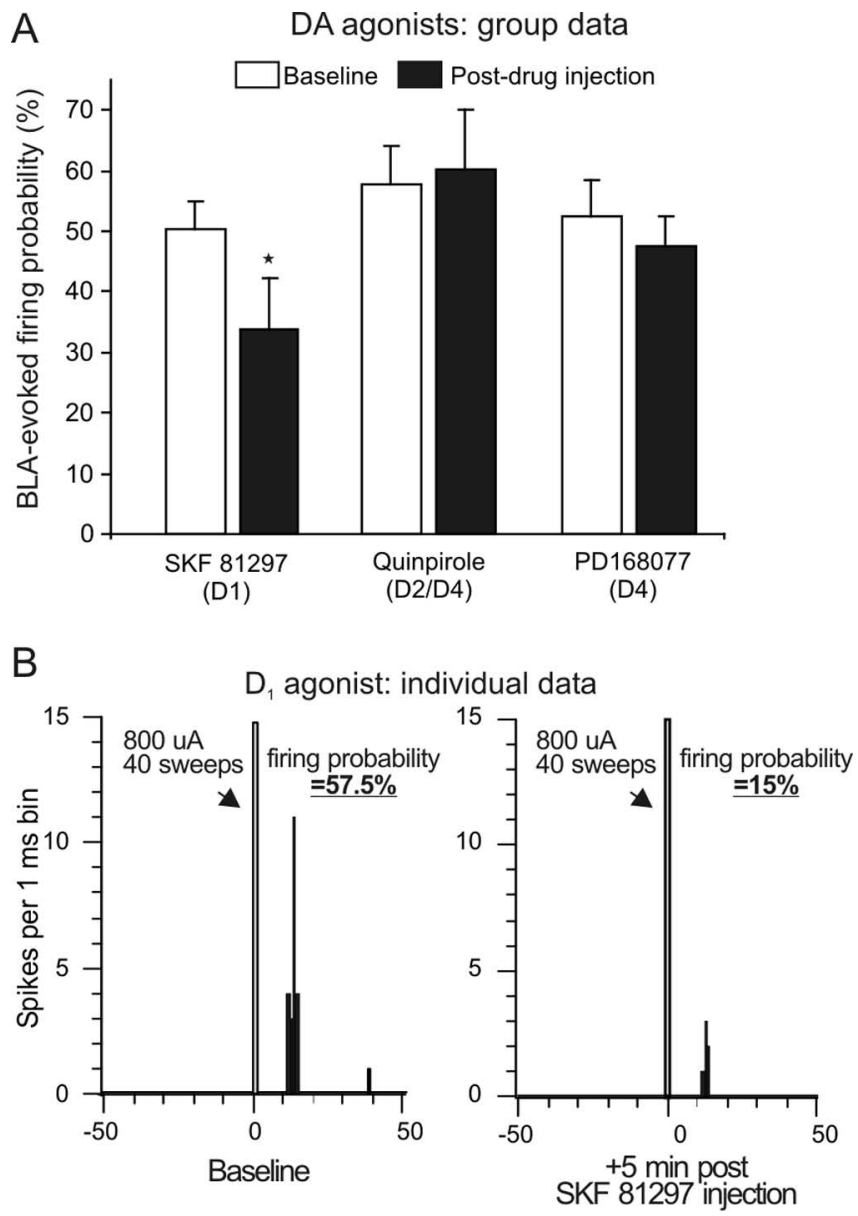

Figure 5. Administration of a $D_{1}$ (but not $D_{2} / D_{4}$ ) DA receptor agonist attenuates BLAevoked firing of $\mathrm{mPFC}$ neurons. $A$, Mean \pm SEM firing probability evoked by single-pulse stimulation of the BLA before drug administration (baseline; white bar) and after systemic administration of DA agonists selective for $D_{1}$ (SKF 81297), $D_{2} / D_{4}$ (quinpirole), or $D_{4}$ (PD-168,077) receptors (black bars). ${ }^{*} p<0.05$ versus baseline. $B$, PSTH obtained from one neuron during baseline stimulation (left) or 5 min after injection of SFK 81297 (right).

these neurons $\left(F_{(1,6)}=6.17 ; p=0.048\right)$ (Table 2). Administration of the selective $\mathrm{D}_{4}$ agonist PD-168,077 $(1 \mathrm{mg} / \mathrm{kg} ; n=7)$ did not alter BLA-evoked firing or the spontaneous firing rates of $\mathrm{BLA} \rightarrow \operatorname{mPFC}(+)$ neurons (both $F$ values $\leq 1.1$; both $p$ values $\geq 0.335)$. Thus, in contrast to what was observed for BLA $\rightarrow$ $\operatorname{mPFC}(-)$ neurons, activation of $\mathrm{D}_{1}$ (but not $\mathrm{D}_{2}$ or $\mathrm{D}_{4}$ ) receptors attenuates $\mathrm{BLA}$-evoked excitatory responses of $\mathrm{mPFC}$ neurons.

\section{Anatomical distributions of $\mathrm{BLA} \rightarrow \mathrm{mPFC}(+)$ and $\mathrm{mPFC}(-)$ neurons in the mPFC}

The locations of mPFC neurons subjected to dopaminergic manipulations are presented in Figure $6 A$. A proportion of both BLA $\rightarrow \operatorname{mPFC}(-)$ and $\operatorname{mPFC}(+)$ neurons were activated antidromically by stimulation of either the NAc or the VTA (Fig. 7A). This indicates that a proportion of $\mathrm{MPFC}$ neurons that receive either direct or indirect projections from the BLA in turn send projections to either the ventral striatum or the midbrain DA cell bodies. Photomicrographs of representative stimulating electrode placements are shown in Figure $6 B-D$.

\section{Antidromic activation from the BLA}

Over the course of this study, we also encountered 22 neurons that were activated antidromically by BLA stimulation. We com-

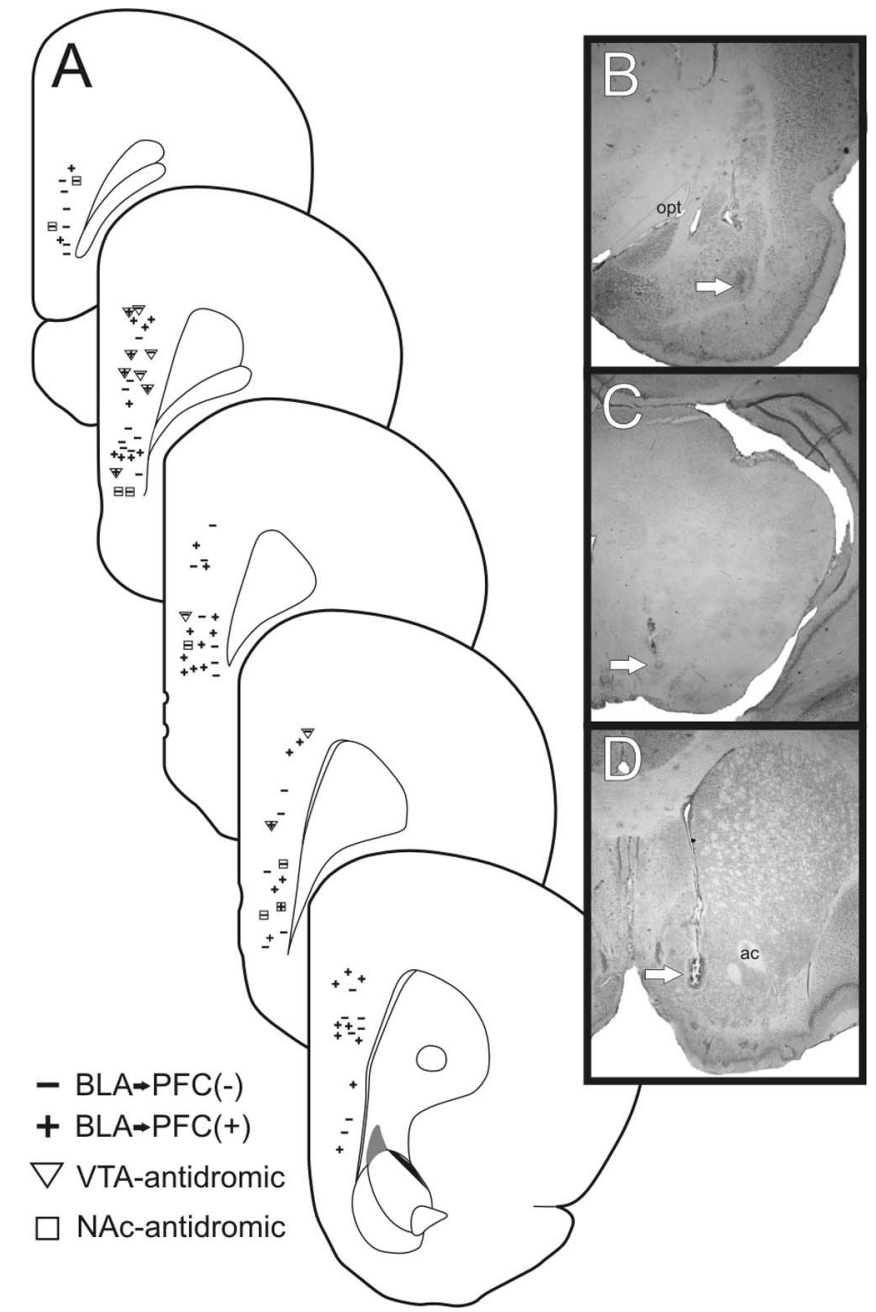

Figure 6. Histology. $A$, Schematic of coronal sections of the rat $\mathrm{mPFC}$ showing representative placements of recording electrodes where BLA-evoked inhibitory $(-)$ and excitatory $(+)$ responses were observed. BLA $\rightarrow \mathrm{MPFC}$ neurons that were antidromically activated by the VTA or NAc are represented by triangles and squares, respectively. $\boldsymbol{B}-\boldsymbol{D}$, Photographs of representatives placement of stimulating electrode in the BLA $(\boldsymbol{B})$, the VTA $(\boldsymbol{C})$, and the NAC (D). Arrows highlight the location of stimulating electrode placements. Opt, Optic tract; ac, anterior commissure.

pared the latencies of BLA-evoked antidromic responses with the monosynaptic response latencies of orthodromically evoked excitatory responses in $\mathrm{BLA} \rightarrow \operatorname{mPFC}(+)$ neurons. BLA-evoked antidromic responses in $\mathrm{mPFC}$ neurons generally occurred at longer latencies than orthodromic responses $\left(t_{(64)}=5.02\right.$; $p=0.0001)($ Fig. $7 B)$, and the mode of antidromic responses $(21$ $\mathrm{ms}$ ) was substantially higher than the modal orthodromic response latency (12 ms) (Fig. $7 B, C)$. Thus, orthodromic action potentials originating in the BLA and terminating in the $\mathrm{mPFC}$ tend to arrive sooner than antidromically activated action potentials that backpropagate through descending mPFC axons terminating in the BLA, as has been reported in cats (Likhtik et al., 2005). Given these findings, it is likely that the excitatory responses to BLA stimulation reported here were attributable primarily to activation of ascending glutamatergic projections from the BLA to the MPFC and not attributable to antidromic activation of recurrent axon collaterals originating in the MPFC and terminating in the BLA.

It is more difficult to determine with certainty the mechanisms that underlie BLA-evoked inhibitory responses. However, 

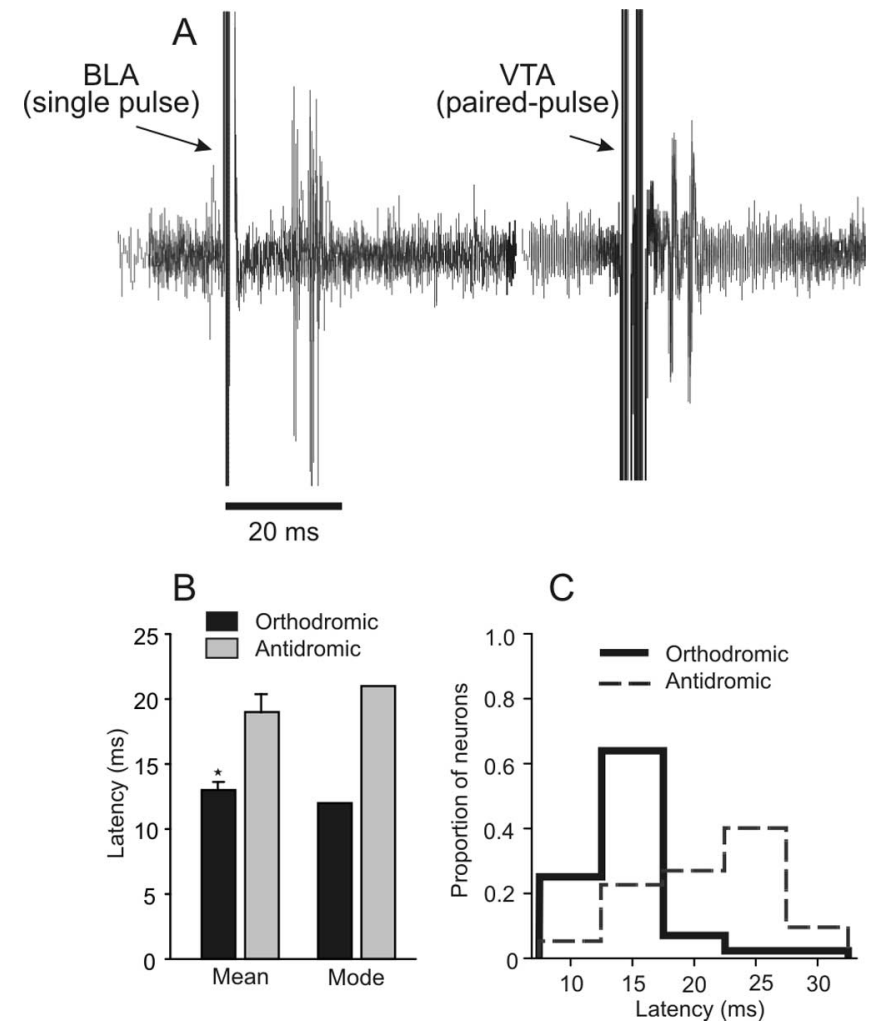

Figure 7. Antidromic activation of $B L A \rightarrow m P F C$ neurons. $A$, Five overlaid traces recorded from one BLA $\rightarrow \mathrm{mPFC}(+)$ neuron that fired orthodromic spikes after single-pulse BLA stimulation (left). This same neuron also displayed antidromic spikes in response to stimulation of the VTA (right; 5 traces). Note the spike jitter of the orthodromic response, whereas the antidromic response follows high-frequency paired-pulse stimulation at a constant latency. $\boldsymbol{B}$, Mean and modal response latencies of BLA-evoked orthodromic excitatory responses (black bars) and BLA-evoked antidromic responses (gray bars). The axons of BLA neurons projecting to the mPFC have a shorter conduction time than $\mathrm{MPFC}$ axons terminating in the BLA. ${ }^{*} p<0.05$. C, Distribution of BLA-evoked orthodromic (thick lines) and antidromic (broken lines) response latencies. Bin width, $5 \mathrm{~ms}$.

several pieces of evidence suggest that these effects are more likely to be attributable to activation of ascending glutamatergic projections from the BLA rather than recurrent collaterals of $\mathrm{mPFC}$ axons. First, our stimulating electrodes were implanted in the caudal BLA, whereas projections originating from the mPFC terminate in the more rostral regions of the BLA (Sesack et al., 1989; McDonald et al., 1996). The placement of our stimulating electrodes combined with relatively low stimulation currents would therefore minimize antidromic activation of mPFC axons terminating in the BLA. Second, the above-mentioned latency data indicates that evoked monosynaptic excitatory responses were likely attributable to activation of ascending projections. This suggests that the evoked inhibitory responses, putatively mediated by glutamatergic inputs activating GABAergic interneurons and in turn inhibiting $\mathrm{MPFC}$ pyramidal neurons, were also attributable to orthodromic activation of ascending BLA inputs. Third, almost $60 \%$ of the BLA $\rightarrow \operatorname{mPFC}(-)$ neurons recorded here displayed onset latencies of evoked inhibition shorter than the modal latency of antidromic spikes $(21 \mathrm{~ms})$, indicating that, at least for these cells, these responses were mediated by activation of ascending BLA projections. Additional evidence comes from paired recordings from pyramidal and fast-spiking interneurons obtained from PFC neurons in vitro. Disynaptic IPSPs in pyramidal cells evoked by local cortical stimulation display longer and more variable latency than preceding monosynaptic
EPSPs, taking 5-15 ms to reach peak amplitude of the inhibitory response (Gao et al., 2003; Povysheva et al., 2006). One reason for this is that the preceding monosynaptic EPSP initially occludes disynaptic IPSP. Assuming that, in the present study, BLA stimulation evoked an initial "subthreshold" EPSP (average latency, $12 \mathrm{~ms}$ ) followed by a slower-onset and longer-lasting IPSP, the average onset of evoked inhibition would be expected to be variable, with an average latency of 25-30 ms. Thus, although we cannot completely exclude that in some instances BLA stimulation activated recurrent collaterals, the above mentioned findings strongly support the notion that the BLA-evoked inhibitory responses, like the monosynaptic excitatory responses, were attributable primarily to activation of ascending glutamatergic projections from the BLA to the mPFC.

\section{Discussion}

Here we report that DA modulates both inhibitory and excitatory transmission in the BLA $\rightarrow$ mPFC pathway in a dissociable manner. VTA stimulation or local application of DA reduces both BLA-evoked inhibitory and excitatory responses in separate populations of mPFC neurons. Administration of DA receptor agonists revealed that $D_{2}$ and $D_{4}$ receptors reduce BLA-evoked inhibition, whereas $D_{1}$ receptors attenuate BLA-evoked firing of mPFC neurons. Moreover, the attenuation of evoked firing by DA is dependent on the frequency of impulse traffic in the BLA $\rightarrow$ $\mathrm{mPFC}$ pathway; suppression of BLA-evoked firing is offset when the BLA is activated with a higher-frequency train of pulses. Because the majority of our dopaminergic manipulations were systemic, we cannot completely rule out that these effects may also be mediated by activation of DA receptors in other brain regions. Nevertheless, the present findings suggest that, by attenuating BLA-mediated inhibition that occurs in the majority of mPFC neurons, DA shifts the balance of excitatory and inhibitory transmission in this pathway, resulting in a net increase in the excitatory influence that the BLA exerts over populations of $\mathrm{mPFC}$ neurons.

\section{DA modulation of BLA-evoked inhibition}

The most prominent effect of BLA stimulation was an inhibition of spontaneous firing, consistent with previous reports (PerezJaranay and Vives, 1991; Ishikawa and Nakamura, 2003; Dilgen and O'Donnell, 2005, 2006). The majority of glutamatergic projections from the BLA synapse onto spines of mPFC pyramidal neurons but some also synapse onto parvalbumin-positive GABAergic interneurons (Gabbott et al., 1997, 2006). These local feedforward inhibitory circuits can suppress firing of large groups of neurons via widespread projections to the soma and initial axonal segments of mPFC pyramidal cells. In the present study, the use of extracellular recordings did not permit detection of subthreshold EPSPs evoked by BLA stimulation, only spike firing. It is therefore likely that a greater proportion of $\mathrm{MPFC}$ neurons receive direct excitatory inputs from the BLA, but activation of these inputs alone is not sufficient to drive spike firing. Indeed, preliminary findings from Dilgen and O'Donnell $(2005,2006)$ using in vivo intracellular recordings indicate that stimulation of the BLA induces subthreshold EPSPs followed by an IPSP in many $\mathrm{mPFC}$ neurons but rarely induced spike firing. Thus, although activation of the BLA may evoke subthreshold excitatory responses in a larger population of $\mathrm{mPFC}$ neurons, it appears that, under basal conditions, the net effect of this activation is inhibition of firing in a majority of mPFC neurons.

Activation of $\mathrm{D}_{2}$ or $\mathrm{D}_{4}$ receptors caused a pronounced reduction in BLA-evoked inhibition. Insight into how these receptors 
may reduce feedforward inhibition comes from in vitro electrophysiological studies of mPFC neurons. Application of either $\mathrm{D}_{2} / \mathrm{D}_{4}$ agonist quinpirole or the $\mathrm{D}_{4}$ agonist PD-168,077 reduces GABA-mediated inhibitory potentials by decreasing GABA release and reducing the sensitivity or conductance of postsynaptic $\mathrm{GABA}_{\mathrm{A}}$ receptors on $\mathrm{mPFC}$ pyramidal neurons (Seamans et al., 2001b; Wang et al., 2002). These findings suggest that, in the present study, increases in DA receptor activity would attenuate the GABA-mediated responses in $\mathrm{mPFC}$ pyramidal neurons driven by feedforward inhibitory circuits originating in the BLA. The attenuation of BLA-driven inhibition by $\mathrm{D}_{2} / \mathrm{D}_{4}$ receptors would disinhibit mPFC neurons, potentially increasing the impact that excitatory inputs from the BLA and other brain regions (e.g., the hippocampus) exert over mPFC activity (Ishikawa and Nakamura, 2003). It follows that blockade of these DA receptors could attenuate spike firing of $\mathrm{mPFC}$ neurons driven by glutamatergic BLA inputs. Indeed, Laviolette et al. (2005) showed that $\mathrm{mPFC}$ neurons receiving monosynaptic excitatory inputs from the BLA increase firing when rats are exposed to an odor associated with footshock, yet these responses were blocked by a $\mathrm{D}_{4}$ antagonist. Together, these findings indicate that, after presentation of emotionally salient stimuli, $\mathrm{D}_{2} / \mathrm{D}_{4}$ receptor activity can facilitate BLA-driven excitation of MPFC pyramidal cells, reducing feedforward inhibition that the BLA normally exerts over populations of $\mathrm{mPFC}$ neurons.

\section{DA modulation of BLA-evoked excitation}

Phasic activation of DA neurons induced a robust, fast-acting suppression of BLA-evoked excitatory responses in MPFC neurons, suggesting that this effect is mediated both by a fast-onset, GABA-mediated IPSP (Lewis and O'Donnell, 2000; Lavin et al., 2005) as well as the release of DA. However, this phenomenon was frequency dependent; firing evoked by $20 \mathrm{~Hz}$ train stimulation of the BLA was substantially less inhibited. Similar effects have been observed in vitro using $20 \mathrm{~Hz}$ stimulation of nonspecified excitatory inputs to mPFC neurons (Seamans et al., 2001a). In that study, application of a $D_{1}$ receptor agonist reduced EPSPs evoked in early parts of the train but enhanced EPSPs in latter parts of the train. Likewise, stimulation of the VTA also attenuates hippocampal-evoked firing of mPFC neurons in a similar, frequency-dependent manner, although it appears to do so via actions on $\mathrm{D}_{2}$ receptors (Floresco and Grace, 2003). It is notable that reward-related stimuli induce burst firing of DA neurons (Schultz, 1998) and higher-frequency activity in the BLA (Ono et al., 1995; Pratt and Mizumori, 1998). This coincidental increase in activity by neurons in both nuclei would ensure that affective signals from the BLA could evoke spike firing in $\mathrm{mPFC}$ neurons when midbrain DA neurons (processing information about reward-predicting stimuli) fire in a burst mode. The simultaneous activation of both of these pathways could in turn facilitate long-term increases in strength of BLA $\rightarrow$ mPFC synapses (Gurden et al., 1999; Laviolette et al., 2005; Young and Yang, 2005; Matsuda et al., 2006).

Local application of DA or administration of $\mathrm{D}_{1}$ (but not $\mathrm{D}_{2} /$ $\mathrm{D}_{4}$ ) agonists also attenuated BLA-evoked firing in mPFC neurons, although these effects were less pronounced than those induced by VTA stimulation. This indicates that prolonged increases in DA receptor tone moderately attenuate the excitatory impact that BLA inputs exert over mPFC neural activity. Although the mechanisms by which $\mathrm{D}_{1}$ receptors suppress BLAevoked firing are unclear, there is evidence to suggest that this effect may be mediated by DA acting on presynaptic glutamate terminals of BLA axons (Paspalas and Goldman-Rakic, 2005).
First, suppression of evoked firing induced by SKF 81297 was not accompanied by a decrease in the spontaneous firing rate. Second, $\mathrm{D}_{1}$ receptor activation attenuates both excitatory responses in the mPFC evoked by local stimulation and BLA-evoked responses in the NAc via a presynaptic mechanism (Floresco et al., 2001; Gao et al., 2001; Seamans et al., 2001a; Charara and Grace, 2003; Mair and Kauer, 2007). Furthermore, we observed a dramatic alteration in the paired-pulse ratio of BLA-evoked firing after VTA stimulation, which suggests a presynaptic mode of action (Fig. 4D).

Although we observed that DA can modulate BLA-evoked excitatory and inhibitory responses in the $\mathrm{MPFC}$, neurochemical studies have shown that high-frequency stimulation of the BLA causes a prolonged increase in mesocortical DA release (Jackson and Moghaddam, 2001). This effect is likely attributable to activation of $\mathrm{mPFC}$ neurons, which in turn project to the VTA, given that $(1)$ we observed a number of $\mathrm{BLA} \rightarrow \operatorname{mPFC}(+)$ neurons that were antidromically activated by VTA stimulation and (2) DA neurons that receive $\mathrm{mPFC}$ input send reciprocal projections to the mPFC (Carr and Sesack, 2000). Thus, the intrinsic connectivity of BLA-mPFC-VTA circuits seems designed to promote prolonged increases in DA release concomitant with increased activation of the BLA, as may occur in response to stimuli of high emotional salience, such as stress, fear, or reward. Based on the present data, DA release facilitated by the BLA would be expected to attenuate BLA-driven inhibitory responses (via $\mathrm{D}_{2} / \mathrm{D}_{4}$ receptors) but have a minimal effect on BLA-evoked firing of $\mathrm{mPFC}$ neurons. These mechanisms working in concert may play a biasing role, so that activation of BLA $\rightarrow$ mPFC projection neurons by emotionally relevant events would be more likely to exert a net increase in firing in $\mathrm{mPFC}$ neuronal networks. The resultant increase in $\mathrm{mPFC}$ neural activity may in turn facilitate response selection to deal with these events accordingly.

\section{Functional implications}

The present findings indicate that DA mediates the balance between excitatory and inhibitory responses in populations of $\mathrm{mPFC}$ neurons and imply that disruptions in $\mathrm{mPFC} D \mathrm{DA}$ receptor activity would impair behaviors mediated by BLA-mPFC circuits. Accordingly, local blockade of DA receptors, in particular the $\mathrm{D}_{4}$ subtype, impairs both acquisition and extinction of a conditioned fear response (Pezze et al., 2003; Laviolette et al., 2005; Pfeiffer and Fendt, 2006). Similarly, different forms of decision making dependent on BLA-mPFC circuits are also impaired by depletion of DA or blockade of $\mathrm{D}_{1}, \mathrm{D}_{2}$, or $\mathrm{D}_{4}$ receptors in the mPFC (Schweimer et al., 2005; Floresco and Magyar, 2006; Floresco and Ghods-Sharifi, 2007). These findings indicate that dopaminergic mediation of excitatory and inhibitory transmission in the BLA $\rightarrow$ mPFC pathway plays an important role in mediating emotional and cognitive processes governed by temporalfrontal lobe circuitry. Disruption of dopaminergic regulation in these circuits would therefore be expected to lead to pathophysiological disturbances in emotional processes present in a number of psychiatric disorders. For example, the present findings suggest that increased BLA activity combined with deficient mesocortical DA signaling would result in a pathological hypoactivation in the $\mathrm{mPFC}$. In fact, this profile of increased amygdalar and reduced $\mathrm{mPFC}$ activation is observed in patients with depression, in which a deficiency in DA transmission is thought to contribute to this disorder (Haldane and Frangou, 2004; Siegle et al., 2007). In contrast, a hypersensitive mesocortical DA system, as may be induced by psychostimulant abuse, would be expected to lead to increased mPFC activation and associated drug craving 
in response to drug-related stimuli, processed by the BLA (Childress et al., 1999). Thus, perturbations in mPFC DA signaling, which alter neural activity in BLA-mPFC circuitry, may be a contributing factor to emotional and cognitive disturbances associated with these disorders. As such, psychopharmacological therapies designed to normalize DA transmission in the mPFC may prove useful in ameliorating the symptoms of these disorders.

\section{References}

Bechara A (2005) Decision making, impulse control and loss of willpower to resist drugs: a neurocognitive perspective. Nat Neurosci 8:1458-1463.

Bechara A, Damasio H, Damasio AR, Lee GP (1999) Different contributions of the human amygdala and ventromedial prefrontal cortex to decisionmaking. J Neurosci 19:5473-5481.

Burette F, Jay TM, Laroche S (1997) Reversal of LTP in the hippocampal afferent fiber system to the prefrontal cortex in vivo with low-frequency patterns of stimulation that do not produce LTD. J Neurophysiol 78:1155-1160.

Carr DB, Sesack SR (2000) Projections from the rat prefrontal cortex to the ventral tegmental area: target specificity in the synaptic associations with mesoaccumbens and mesocortical neurons. J Neurosci 20:3864-3873.

Charara A, Grace AA (2003) Dopamine receptor subtypes selectively modulate excitatory afferents from the hippocampus and amygdala to rat nucleus accumbens neurons. Neuropsychopharmacology 28:1412-1421.

Childress AR, Mozley PD, McElgin W, Fitzgerald J, Reivich M, O’Brien CP (1999) Limbic activation during cue-induced cocaine craving. Am J Psychiatry 156:11-18.

Conde F, Maire-Lepoivre E, Audinat E, Crepel F (1995) Afferent connections of the medial frontal cortex of the rat. II. Cortical and subcortical afferents. J Comp Neurol 352:567-593.

Dilgen JE, O’Donnell P (2005) In vivo intracellular recordings from the medial prefrontal cortex reveal an inhibitory response to basolateral amygdala stimulation. Soc Neurosci Abstr 31:271.7.

Dilgen JE, O'Donnell P (2006) Basolateral amygdala projections to the medial prefrontal cortex: an inhibitory pathway? Soc Neurosci Abstr 32:730.7.

Drevets WC (2003) Neuroimaging abnormalities in the amygdala in mood disorders. Ann NY Acad Sci 985:420-444.

Floresco SB, Ghods-Sharifi S (2007) Amygdala-prefrontal cortical circuitry regulates effort-based decision making. Cereb Cortex 17:251-260.

Floresco SB, Grace AA (2003) Gating of hippocampal-evoked activity in prefrontal cortical neurons by inputs from the mediodorsal thalamus and ventral tegmental area. J Neurosci 23:3930-3943.

Floresco SB, Magyar O (2006) Mesocortical dopamine modulation of executive functions: beyond working memory. Psychopharmacology 188:567-585.

Floresco SB, Blaha CD, Yang CR, Phillips AG (2001) Modulation of hippocampal and amygdalar-evoked activity of nucleus accumbens neurons by dopamine: cellular mechanisms of input selection. J Neurosci 21:2851-2860.

Gabbott PL, Dickie BG, Vaid RR, Headlam AJ, Bacon SJ (1997) Localcircuit neurones in the medial prefrontal cortex (areas 25, 32 and 24b) in the rat: morphology and quantitative distribution. J Comp Neurol 377:465-499.

Gabbott PL, Warner TA, Busby SJ (2006) Amygdala input monosynaptically innervates parvalbumin immunoreactive local circuit neurons in rat medial prefrontal cortex. Neuroscience 139:1039-1048.

Gao WJ, Krimer LS, Goldman-Rakic PS (2001) Presynaptic regulation of recurrent excitation by D1 receptors in prefrontal circuits. Proc Natl Acad Sci USA 98:295-300.

Gao WJ, Wang Y, Goldman-Rakic PS (2003) Dopamine modulation of perisomatic and peridendritic inhibition in prefrontal cortex. J Neurosci 23:1622-1630.

Garris PA, Wightman RM (1994) Different kinetics govern dopaminergic transmission in the amygdala, prefrontal cortex, and striatum: an in vivo voltammetric study. J Neurosci 14:442-450.

Gaspar P, Bloch B, LeMoine C (1995) D1 and D2 receptor gene expression in rat frontal cortex: cellular localization in different classes of efferent neurons. Eur J Neurosci 7:1050-1063.

Glase SA, Akunne HC, Georgic LM, Heffner TG, MacKenzie RG, Manley PJ,
Pugsley TA, Wise LD (1997) Substituted [(4-phenylpiperazinyl)-methyl]benzamides: selective dopamine D4 agonists. J Med Chem 40:1771-1772.

Gurden H, Tassin J-P, Jay TM (1999) Integrity of the mesocortical dopaminergic system is necessary for complete expression of in vivo hippocampal-prefrontal cortex long-term potentiation. Neuroscience 94:1019-1027.

Haldane M, Frangou S (2004) New insights help define the pathophysiology of bipolar affective disorder: neuroimaging and neuropathology findings. Prog Neuropsychopharmacol Biol Psychiatry 28:943-960.

Homayoun H, Moghaddam B (2006) Bursting of prefrontal cortex neurons in awake rats is regulated by metabotropic glutamate 5 (mGlu5) receptors: rate-dependent influence and interaction with NMDA receptors. Cereb Cortex 16:93-105.

Hotte M, Thuault S, Lachaise F, Dineley KT, Hemmings HC, Nairn AC, Jay TM (2006) $\mathrm{D}(1)$ receptor modulation of memory retrieval performance is associated with changes in PCREB and pDARPP-32 in rat prefrontal cortex. Behav Brain Res 171:127-133.

Ishikawa A, Nakamura S (2003) Convergence and interaction of hippocampal and amygdalar projections within the prefrontal cortex in the rat. J Neurosci 23:9987-9995.

Jackson ME, Moghaddam B (2001) Amygdala regulation of nucleus accumbens dopamine output is governed by the prefrontal cortex. J Neurosci 21:676-681.

Jay TM, Glowinski J, Thierry AM (1995) Inhibition of hippocampoprefrontal cortex excitatory responses by the mesocortical DA system. NeuroReport 6:1845-1848.

Khan ZU, Gutierrez A, Martin R, Penafiel A, Rivera A, De La Calle A (1998) Differential regional and cellular distribution of dopamine D2-like receptors: an immunocytochemical study of subtype-specific antibodies in rat and human brain. J Comp Neurol 402:353-371.

Kita H, Kitai ST (1990) Amygdaloid projections to the frontal cortex and the striatum in the rat. J Comp Neurol 298:40-49.

Lavin A, Nogueira L, Lapish CC, Wightman RM, Phillips PE, Seamans JK (2005) Mesocortical dopamine neurons operate in distinct temporal domains using multimodal signaling. J Neurosci 25:5013-5023.

Laviolette SR, Lipski WJ, Grace AA (2005) A subpopulation of neurons in the medial prefrontal cortex encodes emotional learning with burst and frequency codes through a dopamine $\mathrm{D}_{4}$ receptor-dependent basolateral amygdala input. J Neurosci 25:6066-6075.

Lewis BL, O’Donnell P (2000) Ventral tegmental area afferents to the prefrontal cortex maintain membrane potential "up" states in pyramidal neurons via D1 dopamine receptors. Cereb Cortex 10:1168-1175.

Likhtik E, Pelletier JG, Paz R, Pare D (2005) Prefrontal control of the amygdala. J Neurosci 25:7429-7437.

McDonald AJ (1991) Organization of amygdaloid projections to the prefrontal cortex and associated striatum in the rat. Neuroscience 44:1-14.

McDonald AJ (1996) Glutamate and aspartate immunoreactive neurons of the rat basolateral amygdala: colocalization of excitatory amino acids and projections to the limbic circuit. J Comp Neurol 365:367-379.

McDonald AJ, Mascagni F, Guo L (1996) Projections of the medial and lateral prefrontal cortices to the amygdala: a Phaseolus vulgaris leucoagglutinin study in the rat. Neuroscience 71:55-75.

Mair RD, Kauer JA (2007) Amphetamine depresses excitatory synaptic transmission at prefrontal cortical layer $\mathrm{V}$ synapses. Neuropharmacology 52:193-199.

Maren S, Quirk GJ (2004) Neuronal signalling of fear memory. Nat Rev Neurosci 5:844-852.

Maroun M, Richter-Levin G (2003) Exposure to acute stress blocks the induction of long-term potentiation of the amygdala-prefrontal cortex pathway in vivo. J Neurosci 23:4406-4409.

Maslowski RJ, Napier TC (1991) Dopamine D1 and D2 receptor agonists induce opposite changes in the firing rate of ventral pallidal neurons. Eur J Pharmacol 200:103-112.

Matsuda Y, Marzo A, Otani S (2006) The presence of background dopamine signal converts long-term synaptic depression to potentiation in rat prefrontal cortex. J Neurosci 26:4803-4810.

Morrow BA, Elsworth JD, Rasmusson AM, Roth RH (1999) The role of mesoprefrontal dopamine neurons in the acquisition and expression of conditioned fear in the rat. Neuroscience 92:553-564.

Mrzijak L, Bergson C, Pappy M, Huff R, Levenson R, Goldman-Rakic PS 
(1996) Localization of dopamine D4 receptors in GABAergic neurons of the primate brain. Nature 381:245-248.

Mulder AB, Arts MPM, Lopes da Silva FH (1997) Short- and long-term plasticity of the hippocampus to nucleus accumbens and prefrontal cortex pathways in the rat, in vivo. Eur J Neurosci 9:1603-1611.

Mulkey RM, Malenka RC (1992) Mechanisms underlying induction of homosynaptic long-term depression in area CA1 of the hippocampus. Neuron 9:967-975.

Muly EC, Szigeti K, Goldman-Rakic PS (1998) $D_{1}$ receptor in interneurons of macaque prefrontal cortex: distribution and subcellular localization. J Neurosci 18:10553-10565.

Nayak S, Cassaday HJ (2003) The novel dopamine D4 receptor agonist (PD 168,077 maleate): doses with different effects on locomotor activity are without effect in classical conditioning. Prog Neuropsychopharmacol Biol Psychiatry 27:441-449.

Ono T, Nishijo H, Uwano T (1995) Amygdala role in conditioned associative learning. Prog Neurobiol 46:401-422.

Paspalas CD, Goldman-Rakic PS (2005) Presynaptic $\mathrm{D}_{1}$ dopamine receptors in primate prefrontal cortex: target-specific expression in the glutamatergic synapse. J Neurosci 25:1260-1267.

Paxinos G, Watson C (1997) The rat brain in stereotaxic coordinates, Ed 3. San Diego: Academic.

Perez-Jaranay JM, Vives F (1991) Electrophysiological study of the response of medial prefrontal cortex neurons to stimulation of the basolateral nucleus of the amygdala in the rat. Brain Res 564:97-101.

Pezze MA, Bast T, Feldon J (2003) Significance of dopamine transmission in the rat medial prefrontal cortex for conditioned fear. Cereb Cortex $13: 371-380$

Pfeiffer UJ, Fendt M (2006) Prefrontal dopamine D4 receptors are involved in encoding fear extinction. NeuroReport 17:847-850.

Piercey MF, Hoffmann WE, Smith MW, Hyslop DK (1996) Inhibition of dopamine neuron firing by pramipexole, a dopamine D3 receptorpreferring agonist: comparison to other dopamine receptor agonists. Eur J Pharmacol 312:35-44.

Pinto A, Sesack SR (1999) Basolateral amygdala afferents to the rat prefrontal cortex: ultrastructural and relation to dopamine afferents. Soc Neurosci Abstr 21:1216.

Pirot S, Jay TM, Glowinski J, Thierry AM (1994) Anatomical and electrophysiological evidence for an excitatory amino acid pathway from the thalamic mediodorsal nucleus to the prefrontal cortex in the rat. Eur J Neurosci 6:1225-1234.

Povysheva NV, Gonzalez-Burgos G, Zaitsev AV, Kroner S, Barrionuevo G, Lewis DA, Krimer LS (2006) Properties of excitatory synaptic responses in fast-spiking interneurons and pyramidal cells from monkey and rat prefrontal cortex. Cereb Cortex 16:541-552.

Pratt WE, Mizumori SJY (1998) Characteristics of basolateral amygdala neuronal firing on a spatial memory task involving differential reward. Behav Neurosci 112:554-570.

Schultz W (1998) Predictive reward signal of dopamine neurons. J Neurophysiol 80:1-27.

Schweimer J, Saft S, Hauber W (2005) Involvement of catecholamine neurotransmission in the rat anterior cingulate in effort-related decision making. Behav Neurosci 119:1687-1692.
Seamans JK, Yang CR (2004) The principal features and mechanisms of dopamine modulation in the prefrontal cortex. Prog Neurobiol 74:1-58.

Seamans JK, Durstewitz D, Christie B, Stevens CF, Sejnowski TJ (2001a) Dopamine D1/D5 receptor modulation of excitatory synaptic inputs to layer V prefrontal cortex neurons. Proc Natl Acad Sci USA 98:301-306.

Seamans JK, Gorelova N, Durstewitz D, Yang CR (2001b) Bidirectional dopamine modulation of GABAergic inhibition in prefrontal cortical pyramidal neurons. J Neurosci 21:3628-3638.

Seeman P, Van Tol HH (1993) Dopamine receptor pharmacology. Curr Opin Neurol Neurosurg 6:602-608.

Sesack SR, Deutch AY, Roth RH, Bunney BS (1989) Topographical organization of the efferent projections of the medial prefrontal cortex in the rat: an anterograde tract-tracing study with Phaseolus vulgaris leucoagglutinin. J Comp Neurol 290:213-242.

Sesack SR, King SW, Bressler CN, Watson SJ, Lewis DA (1995) Electron microscopic visualization of dopamine D2 receptors in the forebrain: cellular, regional, and species comparisons. Soc Neurosci Abstr 21:365.

Shenton ME, Dickey CC, Frumin M, McCarley RW (2001) A review of MRI findings in schizophrenia. Schizophrenia Res 49:1-52.

Shinonaga Y, Takada M, Mizuno N (1994) Topographic organization of collateral projections from the basolateral amygdaloid nucleus to both the prefrontal cortex and nucleus accumbens in the rat. Neuroscience 58:389-397.

Siegle GJ, Thompson W, Carter CS, Steinhauer SR, Thase ME (2007) Increased amygdala and decreased dorsolateral prefrontal BOLD responses in unipolar depression: related and independent features. Biol Psychiatry 61:198-209.

Tang L, Todd RD, Heller A, O’Malley KL (1994) Pharmacological and functional characterization of D2, D3 and D4 dopamine receptors in fibroblast and dopaminergic cell lines. J Pharmacol Exp Ther 268:495-502.

Tierney PL, Degenetais E, Thierry AM, Glowinski J, Gioanni Y (2004) Influence of the hippocampus on interneurons of the rat prefrontal cortex. Eur J Neurosci 20:514-524.

Trantham-Davidson H, Neely LC, Lavin A, Seamans JK (2004) Mechanisms underlying differential $D_{1}$ versus $D_{2}$ dopamine receptor regulation of inhibition in prefrontal cortex. J Neurosci 24:10652-10659.

Tseng KY, Mallet N, Toreson KL, Le Moine C, Gonon F, O’Donnell P (2006) Excitatory response of prefrontal cortical fast-spiking interneurons to ventral tegmental area stimulation in vivo. Synapse 59:412-417.

Wang J, O'Donnell P (2001) D1 dopamine receptors potentiate NMDAmediated excitability increase in layer $\mathrm{V}$ prefrontal cortical pyramidal neurons. Cereb Cortex 11:452-462.

Wang X, Zhong P, Yan Z (2002) Dopamine $\mathrm{D}_{4}$ receptors modulate GABAergic signaling in pyramidal neurons of prefrontal cortex. J Neurosci 22:9185-9193.

Wang X, Zhong P, Gu Z, Yan Z (2003) Regulation of NMDA receptors by dopamine $\mathrm{D}_{4}$ signaling in prefrontal cortex. J Neurosci 23:9852-9861.

Wedzony K, Chocyk A, Mackowiak M, Fijal K, Czyrak A (2001) Cortical localization of dopamine D4 receptors in the rat brainimmunocytochemical study. J Physiol Pharmacol 51:205-221.

Young CE, Yang CR (2005) Dopamine D1-like receptor modulates layerand frequency-specific short-term synaptic plasticity in rat prefrontal cortical neurons. Eur J Neurosci 21:3310-3320. 